\begin{abstract}
LVIII.-On the Isomeric Acids obtained from Coumarin and the Ether's of Hydride of Salicyl.
\end{abstract}

By W. H. Perkin, F.R.S.

Some time since I published an account of two isomeric methylorthoxyphenylacrylic acids, which I designated as $\alpha$ and $\beta$. The former is prepared by treating the compound of coumarin and sodic hydrate with methylic iodide, by which means either its saline compound or methylic ether can be obtained (Chem. Soc. J., 1877, 417-420); the latter, by heating the hydride of methylsalicyl with acetic anhydride and sodic acetate (Chem. Soc. J., 1877, 414). It will be remembered that these acids differ from each other very widely, the fusing points being about $90^{\circ} \mathrm{C}$. apart. The most remarkable fact, however, is that by the action of heat the $\alpha$-acid becomes converted into the $\beta$.

The cause of the isomerism of these bodies being unexplainabletheir formation indicating that they should be identical-it was hoped that by studying their properties and derivatives side by side, and preparing, if possible, some of their homologues, some light might be thrown on this subject.

To render the consideration of the results I have obtained as clear as possible, I have thought it best first to give an account of all the products that have been obtained, together with their analyses, and afterwards to consider their bearing and relationship to each other.

\title{
a.Methylorthoxyphenylacrylic Acid.
}

To purify this acid it has been found useful to crystallise it first from petroleum spirit, in which it is only moderately soluble, and then once or twice from alcohol. It is very soluble in this fluid, and does not crystallise out from it for some time. However, it then forms large magnificent crystals, which refract light like jewels whilst in their mother-liquor, but lose their lustre when removed, as some of the solution dries on the face of the crystals, and renders them dull. This acid also crystallises very well from carbon bisulphide. The crystals belong to the oblique system. Their measurements are given at the end of this paper.

I have already referred to the change which this acid undergoes when heated, whereby it is converted into its isomeride the $\beta$-acid. Experiments have also been made with light, which is found to act in a similar manner, a strong alcoholic solution, when exposed to the 
sun, soon depositing crystals of the $\beta$-acid. The fused acid also changes in a similar manner when the light is concentrated upon it.

To see which rays of light caused this change, test-tubes containing strong solutions of the acid were immersed in variously coloured solutions contained in bottles, a solution of sulphate of quinine, and to make the experiments comparative, water was also taken. After exposure to light for some time, crystals of the $\beta$-acid were formed in the tubes immersed in water and in the blue solution (ammoniacal sulphate of copper), all the others were apparently quite unacted upon. The quinine solution also prevented any change from taking place, so that it is evident that the alteration is due to the action of the violet and ultra-violet rays.

If $\alpha$-methylorthoxyphenylacrylic acid be boiled with dilute hydrochloric acid, it melts, and nothing appears to occur for some time, when it rapidly becomes crystalline. On recrystallising this from alcohol two or three times, it gave on analysis numbers showing that it had not changed in composition. The fusing point, however, had risen to $178^{\circ}$; therefore it evidently had been converted into the $\beta$-acid ; other acids, as dilute sulphuric acid, also induce this change.

\section{Baric a-Methylorthoxyphenylacrylate.}

The above acid easily dissolves in a boiling solution of baric hydrate, forming a pale-yellow solution. After removal of the excess of baric hydrate by carbonic acid, the solution may be concentrated, until somewhat syrupy, without depositing the salt, and on standing for a day or more may remain clear, and then suddenly become a crystalline mass. After a time this changes, and the small crystals which filled the liquid are replaced by rather large transparent ones of a paleyellow tint.

A barium determination of the salt dried at $100^{\circ}$ gave the following result :-

0.2460 of substance gave 0.1147 of $\mathrm{BaSO}_{4}=27 \cdot 41$ per cent. Ba.

The formula $\mathrm{C}_{20} \mathrm{H}_{18} \mathrm{BaO}_{6}$ requires $27 \cdot 26$ per cent. of $\mathrm{Ba}$.

\section{Methylic a-Methylorthoxyphenylacrylate.}

The preparation of this ether has previously been given (Chem. Soc. $J ., 1877,418)$. I find, however, that the digestion of the compound of sodic hydrate and coumarin with methylic iodide and alcohol should not be continued longer than necessary. I generally heat the mixture in a soda-water bottle securely corked and placed in a water-bath, kept at $100^{\circ}$ for about three hours. If the digestion be carried on, say for eight or ten hours, especially if a little excess of methylic 
iodide be present, most of the ether will become converted into the $\beta$-compound.

The boiling point of the ether prepared as above is lower than that I previously gave, probably on account of its greater freedom from the $\beta$-compound, viz., $275-276^{\circ}$. Its specific gravity at $15^{\circ}$ is $1 \cdot 1404$, and at $30^{\circ} 1 \cdot 1277$ compared with water at the same temperatures.

A determination of its magnetic rotary power gave for the yellow ray $2 \cdot 334$, water being taken as 1 .*

With concentrated sulphuric acid it yields a soluble acid.

\section{$\beta$-Methylorthoxyphenylacrylic Acid.}

This acid, as usually prepared from the hydride of methylsalicyl, acetic anhydride, and sodic acetate, is of a pale-yellow colour, and this is only slowly removed by crystallisation from alcohol. If, however, coal-tar naphtha be employed instead of alcohol, it is easily obtained perfectly white, and apparently slightly fluorescent. The acid thus purified melts at $178-179^{\circ}$. The crystals of this body have been measured; they belong to the oblique system. For their description, see the end of this paper.

\section{Methylic $\beta$-Methylorthoxyphenylacrylate.}

This compound was prepared from the above acid by converting it into its chloride with phosphoric chloride, and then adding the chloride by degrees to methyl aleohol. The product was mixed with water to remove the excess of methyl alcohol, \&c. The somewhat thick oily ether was then collected, diluted with ordinary ether, and left to dry over potassium carbonate. It was then distilled; as soon as most of the ordinary ether had been driven over, the thermometer rapidly rose and became stationary at $293^{\circ}$, at which temperature nearly all of the new product came over. It gave on analysis the following numbers :-

0.0975 of substance gave 0.2463 of $\mathrm{CO}_{2}$, and 0.0568 of $\mathrm{OH}_{2}$.

$\begin{array}{ccc}\text { Theory for } \mathrm{C}_{11} \mathrm{H}_{12} \mathrm{O}_{3} . & & \text { Experiment. } \\ \text { Carbon } \ldots \ldots \ldots \ldots \ldots \ldots & 68 \cdot 75 & 68 \cdot 89 \\ \text { Hydrogen } \ldots \ldots \ldots \ldots & 6 \cdot 25 & 6 \cdot 47\end{array}$

Methylic $\beta$-methylorthoxyphenylacrylate is a thick, highly refracting oil. Its specific gravity at $15^{\circ}$ is $1 \cdot 1486$; at $30^{\circ}, 1 \cdot 1362$, cumpared with water at same temperatures.

* Test observations were made at the same time with water and carbon bisulphide, and gave results very nearly identical with those obtained by Becquerel. (Ann. Chem. Phys., 1877, 12, 22.) 
Determinations of its magnetic rotary power for the yellow ray gave 2.389 . The vapour of this ether, as also of its isomeride, when inhaled, causes headache.

With nitric acid it forms an orange-coloured, semi-solid, amorphous mass. Concentrated sulphuric acid yields with it a soluble acid.

\section{a-Ethylorthoxyphenylacrylic Acid.}

$14 \frac{1}{2}$ grams of coumarin were dissolved in a solution of pure sodic hydrate containing 8 grams of alkali. The resulting product was then boiled down to a small bulk, diluted with alcohol, and 32 grams of ethylic iodide added. This mixture was placed in a soda-water bottle, and heated to $100^{\circ}$ for four or five hours. Most of the alcohol was then distilled off, and the residue mixed with ether and water, the latter to remove the sodic iodide. The ethereal solution was then agitated with dilute caustic alkali, and after being separated, placed over potassium carbonate to dry. This contains most of the product of the reaction, viz., ethylic a-ethylorthoxyphenylacrylate, and is separated from the ether by distillation. The dilute alkali with which the ethereal solntion of this ether was washed, yielded when acidified an oil, which solidified after some time. This weighed about 3 grams, and consisted of the new acid. It was crystallised from petroleum spirit, then from alcohol, and analysed. The following numbers were obtained:-

0.1683 of substance gave 0.4242 of $\mathrm{CO}_{2}$, and 0.0942 of $\mathrm{OH}_{2}$.

These numbers agree with those required by the formula-

$$
\mathrm{C}_{11} \mathrm{H}_{12} \mathrm{O}_{3}=\mathrm{C}_{6} \mathrm{H}_{4}\left(\mathrm{OC}_{2} \mathrm{H}_{5}\right)-\mathrm{CH}=\mathrm{CH}-\mathrm{COOH} \text {. }
$$

Theory.

Carbon ........... 68.75

Hydrogen ......... $6 \cdot 25$
Experiment.

$68 \cdot 74$

$6 \cdot 22$

This substance is therefore ethylorthoxyplenylacrylic acid, and from its properties and mode of preparation is evidently the $\alpha$-acid. Its formation resulted from the imperfect action of the ethyl iodide on the sodium compound of the coumarin, one atom of the metal only being attacked. Small quantities of the $\alpha$-acids are usually found associated with their ethers when preparing them from the coumarins from this same cause. Ethylorthoxyphenylacrylic acid can also be easily obtained from its ether by decomposing it with alcoholic potash.

a-ethylorthoxyphenylacrylic acid crystallises very beautifully, and similarly to its methylic homologue, the crystals refracting light very strongly. It melts at $103-104^{\circ}$. It is very soluble in alcohol, and this solvent when supersaturated with it, will sometimes remain perfectly clear for days, but if a single crystal of the acid be placed in it, 
it grows very rapidly and beantifully. It is easily soluble in boiling carbon disulphide, from which it crystallises ont very readily on cooling; in hot petroleum spirit it is moderately soluble.

When exposed to the action of heat it changes into its isomeride the $\beta$-acid.

\section{Ethylic $\alpha$-Ethylorthoxyphenylacrylate.}

The preparation of this ether has already been given. It boils at about $290-291^{\circ}$, but towards the end of the distillation the temperature gradually rises, apparently from the formation of a small quantity of the $\beta$-ether during the operation. On analysis it gave the following numbers :-

0.1328 of substance gave 0.3443 of $\mathrm{CO}_{2}$, and 0.0884 of $\mathrm{OH}_{2}$.

These numbers agree with those required by the formula-

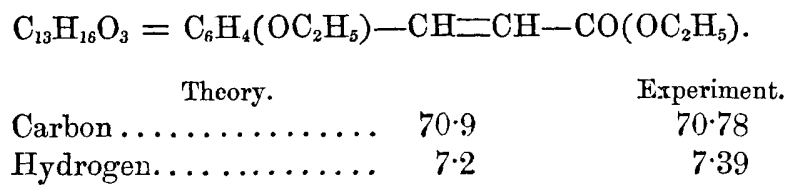

Ethylic ethylorthoxyphenylacrylate is a colourless, transparent, highly refracting oil. Its specific gravity

$$
\begin{aligned}
& \text { at } 15^{\circ} \text { is } 1.084 \\
& \text { at } 30 \text { is } 1.074
\end{aligned}
$$

compared with water at same temperatures.

Determinations of its magnetic rotary power gave for the sodium line $2 \cdot 175$, water $=1$.

\section{B-Ethylorthoxyphenylacrylic Acid.}

This acid was prepared by heating a mixture of hydride of ethyl salicyl, acetic anhydride, and sodic acetate in sealed tubes to $160-$ $170^{\circ}$. The product on cooling solidified to a crystalline mass, and on opening the tubes carbonic anhydride escaped. The contents of the tubes were mixed with water and distilled until oily matter ceased to come over. On cooling, the crude oily acid left in the retort solidified to a crystalline mass, and the aqueous fluid covering it became filled with white needles. After filtering off the solution of sodic acetate, the crude acid was dissolved in a solution of sodic carbonate, and all the neutral oils separated. It was then precipitated with hydrochloric acid, washed, dried, and crystallised from alcohol two or three times.

On analysis it gave the following numbers :-

0.2134 of substance gave 0.5396 of $\mathrm{CO}_{2}$, and 0.1211 of $\mathrm{OH}_{2}$. 


$\begin{array}{ccc}\text { Theory for } \mathrm{C}_{11} \mathrm{H}_{12} \mathrm{O}_{3} & & \text { Experiment. } \\ \text { Carbon } \ldots \ldots \ldots \ldots \ldots \ldots & 68 \cdot 74 & 68 \cdot 96 \\ \text { Hydrogen } \ldots \ldots \ldots \ldots & 6 \cdot 25 & 6.3\end{array}$

$\beta$-ethylorthoxyphenylacrylic differs considerably from the $\alpha$-isomeride. It melts at $135^{\circ}$. It is easily soluble in boiling alcohol, and comes down from it in small prisms as it cools; it is not very soluble in cold alcohol. Boiling benzene dissolves it easily, depositing most of it on cooling in white needles, more colourless than when alcohol is employed. It bears a considerable resemblance to its homologue, $\beta$-methylorthoxyphenylacrylic acid.

\section{Ethylic B-Ethylorthoxyphenylacrylate.}

This ether is prepared from the chloride of the above by acting on it with ethylic alcohol. It boils at $302-304^{\circ}$, and is a thick, highly refracting liquid. A determination of its specific gravity was made, and gave a number nearly identical with that of the $\alpha$-compound, but a little doubt exists as to the purity of the product used in this determination. A specimen obtained by boiling the $\alpha$-ether for some time and fractioning it, gave specific gravity 1.090 at $15^{\circ}$.

\section{Refractive Indices of Methylic $\alpha$ - and $\beta$-Methyl-orthoxyphenyl- ACRYLATE AND ETHYLIC $\alpha$-ETHYLORTHOXYPHENYLACRYLATE.}

I am indebted to the kindness of Dr. J. H. Gladstone for these determinations, and the annexed account of them.

"The following are the refractive indices of the $\alpha$ - and $\beta$-methylorthoxyphenylacrylate of methyl, and of the analogous ethyl compound:-

\begin{tabular}{|c|c|c|c|c|}
\hline Compound. & Temp. & $\mu_{\mathbf{A}}$ & $\mu_{\mathrm{D}}$ & $\mu_{\mathrm{H}}$ \\
\hline $\begin{array}{lll}\text { a-Methylorthoxyphenylacrylate of methyl . } \\
a- & \text { do. } & \text { do. } \\
\beta- & \text { do. } & \text { do. } \\
\beta- & \text { do. } & \text { do. } \\
\text { a-Ethylorthoxyphenylacrylate of ethyl ... }\end{array}$ & $\begin{array}{r}8 \cdot 0^{\circ} \\
10 \cdot 5 \\
9 \cdot 5 \\
100 \\
10 \cdot 0\end{array}$ & $\begin{array}{l}1 \cdot 5577 \\
1 \cdot 5572 \\
1 \cdot 5722 \\
1 \cdot 5722 \\
1 \cdot 5438\end{array}$ & $\begin{array}{l}1 \cdot 5727 \\
1 \cdot 5718 \\
1 \cdot 5912 \\
1 \cdot 5905 \\
1 \cdot 5579\end{array}$ & $\begin{array}{l}1 \cdot 6428 \\
1 \cdot 6421 \\
1 \cdot 6860 ? \\
1 \cdot 6818 ? \\
1 \cdot 6298\end{array}$ \\
\hline
\end{tabular}

"There is a little doubt as to the precise refraction of $\mathrm{H}$ in the $\beta$. methyl compound, as the spectrum was absorbed at about this point.

"The following may be taken as the refractive equivalents for $\mathrm{A}$ and for $\mathrm{H}$, being the mean of the observations :- 


\begin{tabular}{|c|c|c|c|}
\hline Compound. & A. & H. & $\begin{array}{l}\text { Dispersion } \\
\text { equivalent. }\end{array}$ \\
\hline $\begin{array}{l}a-\text { Methylorthoxyphenylacrylate of methyl ... } \\
\text { j-do. do. } \\
\alpha \text {-Ethylorthoxyphenylacrylate of ethyl .... }\end{array}$ & $\begin{array}{r}93 \cdot 42 \\
95 \cdot 10 \\
109 \cdot 76\end{array}$ & $\begin{array}{l}107 \cdot 58 \\
113 \cdot 66 \\
127 \cdot 11\end{array}$ & $\begin{array}{l}14 \cdot 16 \\
18 \cdot 56 \\
17 \cdot 35\end{array}$ \\
\hline
\end{tabular}

"These figures present two points of remarkable interest. 1st. The refraction equivalent is exceedingly high; calculated for the usual values of $\mathrm{C}, \mathrm{H}$, and $\mathrm{O}$, the methyl compound would give us only the refractive equivalent of 73.3 for $\mathrm{A}$; even if all the carbon had the same value as in the ordinary phenyl compounds, it would not give so large a figure; and we must conclude that a portion of it is in the most refractive condition known. The body most analogous to it in this respect is the hydride of cinnamyl. 2nd. The two isomeric modifications of the methyl compound, though they do not differ widely in the refraction equivalent for $A$, are extremely different in dispersion, the increase for the $\beta$-compound being about 30 per cent. This is the only instance with which I am acquainted of two isomeric bodies differing largely in dispersion, but not in their initial refraction.

"The optical properties of the ethyl compound resemble those of its methyl homologue, but are more nearly in accordance with the $\beta$ than with the $\alpha$-modification, the usual difference of refraction-equivalent for $2\left(\mathrm{CH}_{2}\right)$ being $15 \cdot 2 . "$

\section{Action of Nuscent Hydrogen on $\alpha$ - and $\beta$-Methylorthoxyphenylacrylic Acids.}

Separate solutions of the sodic salts of these acids were left in contact with sodium-amalgam for a few hours. On being acidified with hydrochloric acid, they both gave crystalline products apparently identical. They were washed, converted into baric salts, which were purified by recrystallisation, dissolved in water, and again precipitated by hydrochloric acid, and lastly crystallised from petroleum spirit. On analysis they gave the following numbers:-

I. $0 \cdot 1897$ of substance prepared from $\beta$-acid gave 0.4636 of $\mathrm{CO}_{2}$, and 0.1144 of $\mathrm{OH}_{2}$.

II. 0.1252 of substance prepared from $\alpha$-acid gave 0.3064 of $\mathrm{CO}_{2}$, and 0.0747 of $\mathrm{OH}_{2}$.

These numbers give percentages agreeing with those required for the formula-

$$
\mathrm{C}_{10} \mathrm{H}_{12} \mathrm{O}_{3}=\mathrm{C}_{6} \mathrm{H}_{4}\left(\mathrm{OCH}_{3}\right)-\mathrm{CH}_{2}-\mathrm{CH}_{2}-\mathrm{COOH} .
$$




\begin{tabular}{crrr} 
Theory. & & \multicolumn{3}{c}{ Experiment. } \\
Carbon ......... & 66.66 & 66.65 & \multicolumn{1}{c}{ II. } \\
Hydrogen ....... & 6.66 & 6.74 & 6.63
\end{tabular}

It may be called dihydromethylorthoxyphenyacrylic, methylmellilotic, or better, methylorthoxyphenylpropionic acid.

The preparations made with the $\alpha$ - and $\beta$-acids were identical.

This acid melts at $92^{\circ}$; if not purified by conversion into the baric salt, it generally melts at about $87^{\circ}$. It is very soluble in boiling alcohol, and crystallises out from it on cooling in transparent crystals, which when viewed with a lens, are not unlike sodic sulphate. It is only moderately soluble in petroleum spirit, and crystallises from it in small brilliant prisms. Boiling water also dissolves it to a small extent, and deposits it on cooling in lance-like leaves, but if made to crystallise quickly, as oblique plates, which when viewed under the microscope with polarised light, exhibit most beantifully varied and brilliant colours.

Baric Methylorthoxyphenylpropionate.-The acid, when boiled with a solution of baric hydrate dissolves, and after treating the solution with carbonic acid, boiling, and filtering off the baric carbonate formed, a solution of this salt is obtained, which, when concentrated, deposits it in satiny needles, moderately soluble in cold, easily so in hot water.

A solution of this salt gives with silver nitrate an amorphous white precipitate soluble in boiling water, and deposited from it on cooling as a white apparently crystalline powder. With ferric chloride it gives a very pale brown precipitate, which when rubbed contracts to a semi-solid brown mass. With lead acetate it forms a product like lead plaster.

Action of Nitric Acid (sp. gr. 1·5) on a- and B-Methylorthoxyphenylacrylic Acids.

These acids are vigorously acted upon by nitric acid (sp. gr. 1·5), and therefore require to be added to it very slowly, and in small quantities at a time. The nitric acid should also be kept cooled. On pouring the product into water, a drab-coloured substance separates. This was collected, washed, pressed, and crystallised from alcohol several times. The $\alpha$ - and $\beta$-acids both yield the same product, but the $\beta$ gives it in the purest condition, and in largest quantity, and therefore it requires to be recrystallised less frequently. The substance gave the following numbers on analysis:-

I. 0.1474 of substance gave 0.2412 of $\mathrm{CO}_{2}$, and 0.0420 of $\mathrm{OH}_{2}$. II. 0.0953 of substance gave 0.1549 of $\mathrm{CO}_{2}$, and 0.0262 of $\mathrm{OH}_{2}$. 
III. $0 \cdot 1080$ of substance gave 0.1763 of $\mathrm{CO}_{2}$, and 0.0315 of $\mathrm{OH}_{2}$. IV. 0.2192 of substance gave 20 c.c. of nitrogen at $12.5^{\circ}$ and $731 \cdot 7 \mathrm{~mm}$.

These numbers give percentages agreeing with the formula-

$$
\mathrm{C}_{10} \mathrm{H}_{8}\left(\mathrm{NO}_{2}\right)_{2} \mathrm{O}_{3} \text {. }
$$

\begin{tabular}{|c|c|c|c|c|c|}
\hline \multicolumn{6}{|c|}{$\mathrm{C}_{10} \mathrm{H}_{8}\left(\mathrm{NU}_{2}\right)_{2} \mathrm{O}_{3}}$. \\
\hline $\begin{aligned} & \text { Theory. } \\
\text { Carbon } & \ldots \ldots \ldots\end{aligned}$ & $44: 77$ & $\begin{array}{c}\overparen{1 .} \\
44 \cdot 62\end{array}$ & $\begin{array}{c}\text { II. } \\
44.32\end{array}$ & $\begin{array}{l}\text { III. } \\
4452\end{array}$ & IV. \\
\hline Hydrogen .... & 2.98 & $3 \cdot 16$ & $3 \cdot 05$ & $3 \cdot 24$ & - \\
\hline Nitrogen...... & $10 \cdot 44$ & - & - & - & $10 \cdot 55$ \\
\hline
\end{tabular}

The product used in Nos. I, III, and IV was prepared from the $\beta$-acid, the other from the $\alpha$.

This substance is therefore methylorthoxydinitrophenylacrylic acid. It melts at about $192-193^{n}$, but decomposes a little before reaching that point. It is moderately soluble in boiling alcohol, and crystallises out from it on cooling in bright orange-brown clusters of needles. Cold alcohol dissolves it only to a small extent; this is also the case with boiling benzene. It is nearly insoluble in chloroform.

Aqueous potassic hydrate and also ammonia dissolve it, forming a bright yellow coloured solution, from which hydrochloric acid precipitates it as a light drab powder. Alcoholic potassic hydrate also dissolves it, forming a beautiful cerise-coloured solution.

Action of Bromine on a-and $\beta$-Methylorthoxyphenylacrylic Acids.

Weighed quantities of these acids were placed with a vessel of bromine under a bell-jar in the dark. The bromine vapour was rapidly absorbed, and hydrobromic acid formed. After about twelve hours' exposure, the products were removed and placed under another belljar with potassic hydrate for about two days until free from excess of bromine. On weighing the products, it was found that they had both absorbed bromine in the same proportion, viz., 3 atoms. The products were crystallised from benzene, and on analysis gave the following numbers :-

I. 0.1337 of substance gave $0 \cdot 1406$ of $\mathrm{CO}_{2}$, and 0.0279 of $\mathrm{OH}_{2}$.

II. 0.1716 of substance gave 0.1790 of $\mathrm{CO}_{2}$, and 0.0340 of $\mathrm{OH}_{2}$.

No. I was made from the $\alpha$-, and No. II from the $\beta$-acid.

From these numbers it will be seen that this substance has the formula-

VOL. XXXIX.

$$
\mathrm{C}_{10} \mathrm{H}_{9} \mathrm{Br}_{3} \mathrm{O}_{3} \text {. }
$$




\begin{tabular}{|c|c|c|c|}
\hline \multirow{2}{*}{\multicolumn{2}{|c|}{ Theory. }} & \multicolumn{2}{|c|}{ Experiment. } \\
\hline & & I. & II. \\
\hline Carbon .......... & $28 \cdot 75$ & $28 \cdot 68$ & $28 \cdot 45$ \\
\hline Hydrogen ........ & $2 \cdot 13$ & $2 \cdot 31$ & $2 \cdot 20$ \\
\hline
\end{tabular}

The identity of the products made from the $\alpha$-and $\beta$-acids was shown by determinations of their solubilities in chloroform, which gave the following results :-

Substance prepared from $\alpha$-acid 0.413 in 100 of chloroform.

$$
\text { " , } \beta ., 0.43 \quad \text {, " }
$$

Their behavionr with reagents was also identical.

The formation of this substance may be represented thus-

$$
\mathrm{C}_{10} \mathrm{H}_{10} \mathrm{O}_{3}+4 \mathrm{Br}=\mathrm{C}_{10} \mathrm{H}_{9} \mathrm{Br}_{3} \mathrm{O}_{3}+\mathrm{HBr} ;
$$

and as will be seen further on, its constitution may be regarded as-

$$
\mathrm{C}_{6} \mathrm{H}_{3} \mathrm{Br}\left(\mathrm{OCH}_{3}\right)-\mathrm{CHBr}-\mathrm{CHBr}-\mathrm{COOH} \text {. }
$$

It is proposed to call it methylorthoxybromophenyldibromopropionic acid. When heated, this substance melts at about $185-188^{\circ}$ with decomposition. It is moderately soluble in hot benzene, and crystallises from it on cooling in white nodular masses. It is very little soluble in this hydrocarbon when cold. It is very soluble in ether; alcohol appears to decompose it.

Aqueous ammonia dissolves this substance, bat the solution soon becomes milky, especially if heated, and on standing a crystalline product separates out. Dilute sodic carbonate or potassic hydrate also dissolves it, but the solution quickly becomes milky, and, if warmed, a heavy oil separates. A strong solution of caustic alkali, however, does not appear to decompose it.

Boiled with a solution of sodic acetate it gives off carbonic acid with separation of an oil. This oil is carried over very slowly by aqueous vapour. It gave the following numbers on analysis :-

I. 0.1747 of substance gave 0.2290 of $\mathrm{CO}_{2}$, and 0.0420 of $\mathrm{OH}_{2}$.

II. 0.1780 of substance gave 0.2328 of $\mathrm{CO}_{2}$, and 0.0415 of $\mathrm{OH}_{2}$.

\begin{tabular}{|c|c|c|c|}
\hline \multicolumn{2}{|c|}{ 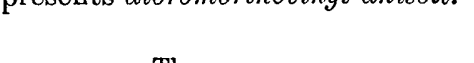 } & \multicolumn{2}{|c|}{ Experiment. } \\
\hline Theory. & & I. & 1I. \\
\hline Carbon ........... & $35 \cdot 06$ & $35 \cdot 75$ & $35 \cdot 66$ \\
\hline Hydrogen........ & $2 \cdot 59$ & $2 \cdot 67$ & $2 \cdot 59$ \\
\hline
\end{tabular}

These numbers show the substance to have the formula $\mathrm{C}_{9} \mathrm{H}_{8} \mathrm{Br}_{2} \mathrm{O}$, which represents dibromorthovinyl-anisoïl.

It is a pale yellow oil, quite viscid when cold; its formation may be represented thus:-

$$
\begin{gathered}
\mathrm{C}_{6} \mathrm{H}_{3} \mathrm{Br}(\mathrm{OCH})-\mathrm{C}_{2} \mathrm{H}_{2} \mathrm{Br}_{2}-\mathrm{COOH}=\mathrm{C}_{6} \mathrm{H}_{3} \mathrm{Br}\left(\mathrm{OCH}_{3}\right)-\mathrm{C}_{2} \mathrm{H}_{2} \mathrm{Br}+ \\
\mathrm{CO}_{2}+\mathrm{HBr} .
\end{gathered}
$$




\section{Action of a Strong Solution of Potassic Hydrate on Methylorthoxy- bromophenyldibromopropionic Acid.}

It has just been stated that a dilate solution of potassic hydrate decomposes methylorthoxybromophenyldibromopropionic acid with separation of an oil. But if a concentrated solution of potassic hydrate (about 50 per cent. was used) be rubbed with it in a mortar, it evidently combines with it, but does not seem to undergo decomposition, apparently because it does not enter into solution. This mixture was heated to $100^{\circ}$ for some time, when potassic bromide formed in quantity. It was then dissolved in water, and found to contain a small quantity of an oily body. This was removed, and the solution acidified, when a crystalline acid, still containing bromine, separated. This acid was collected, washed, and boiled with dilute potassic hydrate, and again precipitated with hydrochloric acid. As this process had not removed the bromine from the new acid, it was washed, dried, and dissolved in boiling benzene, from which it separated on cooling in short white needles, which gave the following numbers on analysis :-

$0 \cdot 1650$ of substance gave 0.2856 of $\mathrm{CO}_{2}$, and 0.0426 of $\mathrm{OH}_{2}$.

These numbers give percentages agreeing with those required by the formula-

$$
\mathrm{C}_{10} \mathrm{H}_{7} \mathrm{BrO}_{3} \text {. }
$$

\begin{tabular}{|c|c|c|}
\hline Theory. & & Experiment. \\
\hline Carbon ............... & $47 \cdot 06$ & $47 \cdot 2$ \\
\hline Hydrogen $\ldots \ldots \ldots \ldots$ & $2 \cdot 74$ & $2 \cdot 86$ \\
\hline
\end{tabular}

This sabstance is methylorthoxybromophenylpropiolic acid. The formation indicates that one of the bromine-atoms in the tribromomethylorthoxyphenylpropionic acid is in the benzene group, as it cannot be removed by boiling alkali. The decomposition may be written thus :-

$$
\mathrm{C}_{6} \mathrm{H}_{3} \mathrm{Br}\left(\mathrm{OCH}_{3}\right)-\mathrm{CHBr}-\mathrm{CHBr}-\mathrm{COOH}=2 \mathrm{HBr}+
$$

Methylorthoxybromphenyldibromopropionic acid.

$$
\mathrm{C}_{6} \mathrm{H}_{3} \mathrm{Br}\left(\mathrm{OCH}_{3}\right)-\mathrm{C} \equiv \mathrm{C}-\mathrm{COOH}
$$

Methylorthoxybromophenylpropiolic acid.

This acid melts at about $168^{\circ}$ with decomposition, becoming yellow. It is moderately soluble in hot, but sparingly in cold benzene. It crystallises from this solvent in short white needles. 


\section{Action of Bromine in a Limited Quantity on a- and B-Methylorthoxy- phenylacrylic Acids.}

\section{Action on a-Methylorthoxyphenylacrylic Acid.}

A weighed quantity of this acid was dissolred in carbon disulphide, and the solution thus obtained when cold was treated by degrees with a 10 per cent. solution of bromine also in carbon disulphide, sufficient being added to form a dibromo-addition product. The bromine quickly combined at first, but more slowly as the last portions were added, a small quantity only of hydrobromic acid being formed. On standing for some time, the sides of the vessel became coated with small brilliant crystals. These were collected, washed with carbon disulphide, and dried in the air, and then in vacuo. They gave on analysis the following numbers:-

I. $0 \cdot 1180$ of substance gave $0 \cdot 1534$ of $\mathrm{CO}_{2}$, and $0 \cdot 0286$ of $\mathrm{OH}_{2}$. II. 0.1405 of substance gave 0.1823 of $\mathrm{CO}_{2}$, and 0.0386 of $\mathrm{OH}_{2}$.

These numbers give percentages agreeing with the formula-

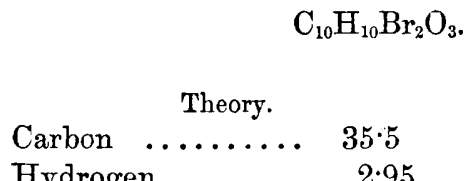

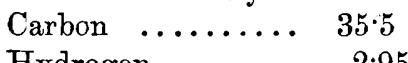

\begin{tabular}{cc} 
Experiment. \\
\hline I. & II. \\
$35 \cdot 44$ & $35 \cdot 38$ \\
2.69 & 3.06
\end{tabular}

The acid is therefore $\alpha$-methylorthoxyphenyldibromopropionic acid. It decomposes if heated for any length of time at $100^{\circ}$. If quickly heated it melts at about $156^{\circ}$, but it does not give any definite fusing point owing to its decomposition. It is moderately soluble in chloroform, and separates from it in flat transparent prisms. Chloroform may be used instead of carbon disulphide in its preparation. It dissolves easily in alcohol with decomposition. The changes it undergoes with various reagents will be found further on.

When exposed to the action of the vapour of bromine for about 24 hours, it gives a product which crystallises from benzene in brilliant apparently oblique crystals, giving on analysis the following numbers :-

0.1006 of substance gave 0.0886 of $\mathrm{CO}_{2}$, and 0.0174 of $\mathrm{OH}_{2}$. These give percentages agreeing with the formula-

$$
\mathrm{C}_{10} \mathrm{H}_{8} \mathrm{Br}_{4} \mathrm{O}_{3} \text {. }
$$

Theory.

Carbon ........... 24:19

Hydrogen ........... 1.61
Experiment.

$23 \cdot 94$

$1 \cdot 92$ 
It may be called methylorthoxydibromophenyldibromopropionic acid. It melts at about $200-202^{\circ}$.

\section{Action on $\beta$-Methylortloxyphenylacrylic Acid.}

A weighed quantity of this acid was dissolved in chloroform, of which it required a considerable volume, being difficultly soluble, the calculated quantity of bromine also in chloroform, to form a dibromoaddition body, was then gradually added. The combination took place as in the case of the $\alpha$-acid, but not so rapidly. After standing for some hours most of the chloroform was distilled off, and the remaining solution on cooling gradually deposited crystals. These were collected and recrystallised from chloroform, and were thus obtained perfectly white. This body gave on analysis the following numbers :-

I. $0 \cdot 1672$ of substance gave $0 \cdot 2191$ of $\mathrm{CO}_{2}$ and $0 \cdot 0468$ of $\mathrm{OH}_{2}$. II. $0 \cdot 1170$ of substance gave $0 \cdot 1524$ of $\mathrm{CO}_{2}$ and 0.0318 of $\mathrm{OH}_{2}$.

This substance has therefore the same formula as the last, viz.:-

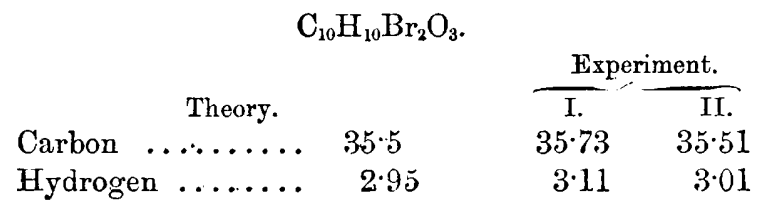

It suffers decomposition at $100^{\circ}$ slowly. Combustion I was made with a product dried at $100^{\circ}$ for some time; II, in vacuo. I was at first inclined to regard this as identical with the product obtained from the $\alpha$-acid, but its fusing point, although indefinite from decomposition, appeared to be somewhat higher. I therefore made determinations of the solubility of the two products, with the following results :-

$$
\begin{aligned}
& \text { Solubility, in } 100 \text { vols. of } \mathrm{CS}_{2} \ldots \ldots \quad \begin{array}{ccc}
\alpha . & \beta . \\
0.074 & 0.4
\end{array} \\
& \begin{array}{llllll}
\prime \quad & \mathrm{CHCl}_{3} \ldots & 1.927 & 6.64
\end{array}
\end{aligned}
$$

These show that the products are isomeric, and not identical; so they have been called $\alpha$ - and $\beta$-methylorthoxphenyldibromopropionic acids. The $\beta$-compound generally forms rather larger and more brilliant crystals than the $\alpha$. It is rather remarkable that although obtained from the least soluble acid it should be the more soluble compound of the two.

$\alpha$ - and $\beta$-methylorthoxyphenyldibromopropionic acids possess the following properties in common. They are easily soluble in ether, freely in alcohol, but with decomposition, the solution becoming acid, 
and moderately in glacial acetic acid. On the addition of aqueous silver nitrate to these solutions, a copious precipitate of silver bromide forms. When shaken with cold water the liquid becomes milky, and if heated to boiling, globules of an oil condense with the steam; the solution also becomes strongly acid. With dilute potassic hydrate, ammonia, sodic carbonate, or sodic acetate, these compounds decompose, with formation of an oil; this decomposition is accelerated by heat. The oil has an odour like that of orthovinylanisoill, and is probably its bromine derivative.

\section{Action of a Strong Solution of Potassic Hydrate on $\alpha$ - and $\beta$-Methyl- orthaxyphenyldibromopropionic Acids.}

I. A quantity of the a-methylorthoxyphenyldibromopropionic acid was rubbed into a paste with a strong solution of potassic hydrate (about 50 per cent.), and then stirred from time to time. After being in contact with the alkali a few hours, the mixture was acidified with dilute hydrochloric acid, and the white crystalline product which resulted collected, washed, and crystallised from boiling water. In this manner it was obtained in glistening needles.

It was then further puritied by recrystallisation from carbon disulphide. A very small quantity of oily product was produced in this reaction. The substance gave the following numbers on analysis:-

$0 \cdot 1130$ of substance gave 0.1931 of $\mathrm{CO}_{2}$, and 0.0379 of $\mathrm{OH}_{2}$.

These give percentages required by the formula-

$$
\mathrm{C}_{10} \mathrm{H}_{9} \mathrm{BrO}_{3} \text {. }
$$

\begin{tabular}{ccc} 
Theory. & \multicolumn{1}{c}{ Experiment. } \\
Carbon.............. & $46 \cdot 69$ & $46 \cdot 6$ \\
Hydrogen $\ldots \ldots \ldots \ldots$. & $3 \cdot 5$ & $3 \cdot 7$
\end{tabular}

It is therefore methylorthoxyphenylbromacrylic acid.

II. Some of the $\beta$-methylorthoxyphenyldibromopropionic acid was treated in the same manner as the $\alpha$ with caustic alkali. It behaved in a similar way, and the product gave on analysis the following numbers :-

I. 0.1561 of substance gave 0.2677 of $\mathrm{CO}_{2}$, and 0.0525 of $\mathrm{OH}_{2}$.

II. $0 \cdot 2485$ of substance gave $0 \cdot 1820$ of $\mathrm{AgBr}$,

which yield percentages analrgous to the above, viz. :-

Theory.

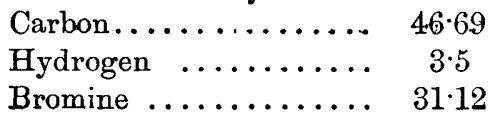

Experiment. 46.75

3.5

$31 \cdot 16$ 
The products obtained from the two dibromo-acids both melt at the same temperature, and from a determination of their solubility in carbon disulphide they are evidently identical, 100 vols. of $\mathrm{CS}_{2}$ at $14^{\circ}$ dissolving 0.31 of the $\alpha$ - and 0.33 of the $\beta$-acid. These determinations were made on only small quantities, otherwise they would probably have been still more accordant. The formation of this acid from these two dibromo-acids is evidently due to removal of hydrobromic acid, thus :- -

$$
\mathrm{C}_{10} \mathrm{H}_{10} \mathrm{Br}_{2} \mathrm{O}_{3}=\mathrm{HBr}+\mathrm{C}_{10} \mathrm{H}_{9} \mathrm{BrO}_{3} \text {. }
$$

Alcoholic potassic hydrate may be employed in the preparation of this acid instead of aqueous, but the product is not generally so pure.

Methylorthoxyphenylbromacrylic acid melts at $169 \cdot 5-171^{\circ}$, and on cooling solidifies to a radiating crystalline mass. The vapour it gives off when heated is very irritating. It can be distilled apparently without decomposition. It is moderately soluble in boiling carbon disulphide, and crystallises out from it on cooling in small brilliant prisms. It is ditficultly soluble in petroleum spirit, but easily so in alcohol. Boiling water dissolves it to a small extent only, but in cold water it is nearly insoluble. In aqueous sodic acetate it is easily soluble, but is precipitated on the addition of hydrochloric acid.

Dilute aqueous potassic hydrate dissolves it freely, but on the addition of a concentrated solution the potassic salt separates out in a crystalline condition. The solution in aqueous ammonia when evaporated in vacuo leaves a crystalline salt soluble in water.

Nitric acid $1.5 \mathrm{sp}$. gr. acts vigorously on this acid, dissolving it, and on the addition of water a light drab-coloured precipitate forms, which conglomerates, but afterwards becomes pulverulent. On crystallising this from alcohol, it is obtained in small yellow needles. It is probably a dinitro-compound of the bromo-acid, as it gives with alcoholic potassic hydrate a beautiful cerise-coloured solution.

\section{Decomposition of Methylorthoxyphenylbromacrylic Acid by Alkalies.}

On boiling a solution of methylorthoxyphenylbromacrylic acid in a dilute solution of potassic hydrate, potassic bromide is formed, and the solution when aciditied with hydrochloric acid deposits a crystalline acid; as this, however, is rather soluble in hot water, it takes some hours before it ceases to separate out. The acid obtained in this manner, after being washed with cold water, was dissolved in boiling water. The resulting solution on cooling became a mass of fine white needles, perfectly filling the liquid, so that the motherliquor could not be poured off freely ; when stirred, however, it became quite fluid, and the crystals could then be easily separated by a filter. 
The mother-liquors when concentrated yielded a further quantity of this product. It was then crystallised from benzene, and on analysis gave the following numbers:-

I. 0.1134 of substance gave 0.2848 of $\mathrm{CO}_{2}$, and 0.0516 of $\mathrm{OH}_{2}$. II. $0.113 \mathrm{I}$ of substance gave 0.2827 of $\mathrm{CO}_{2}$, and 0.0513 of $\mathrm{OH}_{2}$.

These numbers lead to the formula $\mathrm{C}_{10} \mathrm{H}_{8} \mathrm{O}_{3}$.

\begin{tabular}{cccc} 
Theory. & & \multicolumn{2}{c}{ Experiment. } \\
\cline { 3 - 3 } Carbon ......... & $68 \cdot 18$ & $68 \cdot 4$ & II. \\
Hydrogen....... & $4.54 \cdot 17$ \\
& 4.97 & $5 \cdot 03$
\end{tabular}

It is therefore methylorthoxyphenylpropiolic acid, its formation being due to the separation of hydrobromic acid from methylorthoxyphenylbromacrylic acid, thus :-

$\mathrm{C}_{6} \mathrm{H}_{4}\left(\mathrm{OCH}_{3}\right)-\mathrm{C}_{2} \mathrm{HBr}-\mathrm{COOH}=\mathrm{C}_{6} \mathrm{H}_{4}\left(\mathrm{OCH}_{3}\right)-\mathrm{C}_{2}-\mathrm{COOH}+\mathrm{HBr}$.

This acid is moderately soluble in benzene, freely in alcohol and ether, but difficultly in carbon disulphide, the boiling solution in this solvent depositing it.on cooling in brilliant needles. It melts at about $124-126^{\circ}$, with decomposition.

With strong nitric acid it forms a dark greenish indigo-coloured fluid, which soon changes to a reddish-buff colour. The addition of water then causes the separation of yellowish-brown flocks. This product does not give any coloured reaction when heated with an alkali and grape-sugar.

Methylorthoxyphenylpropiolic acid dissolves easily in dilute potassic hydrate. A strong solution added to this causes the potassium salt to separate in minute needles. Sodic hydrate acts in a similar manner, but the salt formed is only a confused crystalline precipitate.

Ammonia dissolves this acid freely, but the solution when evaporated is decomposed.

Silver nitrate gives with a solution of the ammonia salt a copious somewhat curdy white precipitate.

\section{Action of Bromine on the Methylic $\alpha$ - and $\beta$-Methylorthoxyphenyl- acrylates.}

As the dibromo-derivatives of the $\alpha$ - and $\beta$-acid were found to be isomeric, it was thought desirable to see if the ethers would yield analogous products.

I. Action of Bromine on Methylic- $\beta$-Methylorthoxyphenylacrylate.-The following is an account of one out of several operations of this kind, and is taken as it is roughly comparable with an analogous one made with the a-compound given further on. 
3 grams of the $\beta$-compound were nixed with two or three times their bulk of carbon disulphide, and sufficient of a 10 per cent. solution of bromine in carbon disulphide to form a dibromide with the ether, gradually poured in. The bromine readily combined until the last quantities were added, when the fluid remained slightly coloured for some time; very little hydrobromic acid was formed. It was then placed in the dark and allowed to evaporate spontaneously, when crystals began to form after a time, but not until nearly all the carbon disulphide had disappeared. The residue then consisted of a mixture of crystals and a thick mother-liquor. The crystals were separated by washing with a little carbon disulphide, and weighed about 1.7 grams.

This substance was purified by recrystallisation once or twice from carbon disulphide, and gave on analysis the following numbers:-

0.1844 of substance gave 0.2538 of $\mathrm{CO}_{2}$, and 0.0586 of $\mathrm{OH}_{2}$.

These give percentages required by the formula-

$$
\mathrm{C}_{11} \mathrm{H}_{12} \mathrm{Br}_{2} \mathrm{O}_{3} \text {. }
$$

Theory.

$\begin{array}{lrc}\text { Carbon } \ldots \ldots \ldots \ldots \ldots \ldots & 37 \cdot 42 & \text { Experiment. } \\ \text { Hydrogen } \ldots \ldots \ldots \ldots \ldots & 3.41 & 3.53 \\ & \end{array}$

This compound melts at $125^{\circ}$. Its other properties will be referred to further on.

The thick mother-liquors formed at the same time as these crystals, when left exposed to the air for some days, and until perfectly free from carbon disulphide, solidify to a crystalline mass. This was purified by two or three crystallisations from petroleum spirit (b. p. 70$100^{\circ}$ ). It was gradually deposited from this solvent in hard groups of crystals. The weight of the product obtained in this operation after one crystallisation was $3 \cdot 5$ grams, so that it is the principal product of the reaction.

It gave the following numbers on analysis :-

I. $0 \cdot 1215$ of substance gave $0 \cdot 1658$ of $\mathrm{CO}_{2}$, and 0.386 of $\mathrm{OH}_{2}$. II. 0.2438 of substance gave 0.2598 of $\mathrm{AgBr}$.

This substance has the same composition as the one just described.

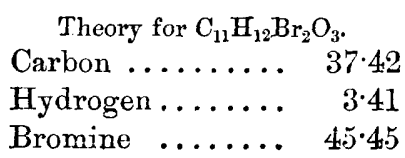

Experiment.

\begin{tabular}{cc}
\hline I. & II. \\
$37 \cdot 21$ & - \\
$3 \cdot 5$ & - \\
- & 45.35
\end{tabular}

It is, however, isomeric, its melting point being only $68^{\circ}$. I propose 
to call it methylic $\beta$-methylorthoxyphenyldibromopropionate. It is exceedingly soluble in carbon disulphide and easily soluble in alcohol.

When treated with cold alcoholic potash it soon dissolves, potassic bromide is deposited, and the solution contains methylorthoxyphenylbromacrylic acid, in combination with the alkali. This, when separated and purified, was found to melt at $169^{\circ}$, and when boiled with a solution of potassic hydrate to decompose into methylorthoxyphenylpropiolate and potassic bromide, so that it is evidently identical with the acid obtained from methylorthoxyphenyldibromopropionic acid already described.

II. Action of Bromine on Methylic a-Methylorthoxyphenylacrylate.3 grams of the $0 .-$ compound were treated with bromine in exactly the same manner as the $\beta$-compound; and the reaction appeared to proceed in the same way, very little hydrobromic acid being formed. The mixture was placed in the dark, and allowed to evaporate spontaneously. In this case, however, crystals rapidly began to form on the sides of the vessel. When the carbon disulphide was mostly evaporated these were collected, washed rapidly with carbon disulphide, dried, and weighed. They weighed 3.5 grams. The mother-liquor on evaporation yielded a second crop of the same crystals, which, however, were unfortunately not weighed.

This crystalline product was purified by recrystallisation from carbon disulphide, and on analysis gave the following numbers :-

I. 0.1749 of substance gave $0.2400 \mathrm{CO}_{2}$, and 0.0582 of $\mathrm{OH}_{2}$.

II. $0 \cdot 2710$ of substance gave 0.2900 of $\mathrm{AgBr}$.

This substance corresponds in composition with the two foregoing ones:-

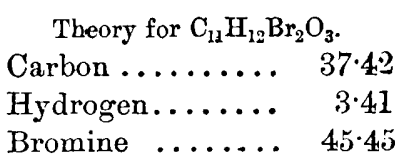

Experiment.

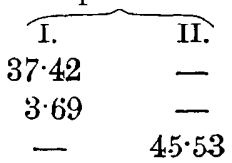

This body, which I propose to call methylic a-methylorthoxyphenyldibromopropionate, melts at $125^{\circ}$; it is evidently the chief product of the reaction, and is identical with the substance obtained in comparatively small quantities with the $\beta$-ether, fusing at the same temperature. A comparison of the solubilities in carbon disulphide of the products from these two ethers was made, and gave the following numbers :-

Bromine-derivative from $\alpha$-compound, $3 \cdot 38$, in 100 vols. $\mathrm{CS}_{2}$.

$$
\text { , " } 3 . \quad \text {, } 3 \cdot 46 \quad \text {, }
$$

This body forms crystals sometimes like calcspar, at other times in 
more complicated forms; they are very transparent. It may be crystallised from alcohol, in which it is easily soluble when boiling, but only moderately when cold; a certain amount, however, undergoes decomposition, the solution becoming acid even in a short time, and strongly so after a few minutes' boiling. It is moderately soluble in boiling petroleum spirit.

Alcoholic potash dissolves the substance slowly, potassic bromide forming. The result of this reaction is, as in the case of the $\beta$-bromine derivative, ordinary methylorthoxyphenylbromacrylic acid, fusing at $169^{\circ}$.

The mother-liquors from the preparation of this $\alpha$-dibromo-compound were found to contain some of the $\beta$-dibromo-compound, fusing at $68^{\circ}$, over 0.7 gram being obtained.

We therefore see the curious result of these experiments to be that the $\alpha$-ether produces as its chief product the dibromo-derivative melting at $125^{\circ}$, with a small quantity of the dibromo-compound melting at $68^{\circ}$. The $\beta$-ether produces as its chief product the dibromo-compound melting at $68^{\circ}$, with a considerable quantity (about 30 per cent. of the theoretical yield) of the dibromo-compound melting at $125^{\circ}$.

In considering these results, it must be borne in mind that the amount of the dibromo-compound fusing at $68^{\circ}$ produced from the $\alpha$-ether is greater than should be produced were the ether perfectly pure, because the $\alpha$-ether in its preparation, having to be distilled, becomes partially changed into the $\beta$-ether, which would principally yield this bromo-body; but these remarks do not in any way apply to the formation of the dibromo-compound melting at $125^{\circ}$, from the $\beta$-ether, as that was perfectly free from the $\alpha$; it must therefore be regarded as a true product of the reaction. This behaviour is somewhat analogous to that of the two hydrobenzoins when treated with phosphoric chloride, the iso-compound giving a chloride only, fusing at $192^{\circ}$, the ordinary hydrobenzoin giving this, and also one fusing at $94^{\circ}$.

\section{Action of Bromine on Ethylic $\alpha$ - and $\beta$-Ethylorthoxyphenylacrylates.}

These ethers, when treated in the same manner as the corresponding methylic compounds, act very similarly. The $\alpha$-product, when the carbon disulphide has evaporated, gives a crystalline product mixed with a honey-like oil, which was removed by petroleum spirit. The product obtained from the $\beta$-ether was at first only an oil, but on keeping it exposed to the air for a number of days crystals separated out. The quantity obtained was, however, only small, the principal product being an oil, which could not be obtained in a fit condition for analysis.

The crystalline products obtained from these ethers were recrystal- 
lised from petroleum, and were found to fuse at the same temperature, so that they are evidently identical. A specimen prepared from the $\alpha$-ether gave on analysis the following numbers:-

0.1363 of substance gave 0.2031 of $\mathrm{CO}_{2}$, and 0.0517 of $\mathrm{OH}_{2}$.

These give percentages agreeing with the formula-

$$
\mathrm{C}_{33} \mathrm{H}_{16} \mathrm{Br}_{2} \mathrm{O}_{3}=\mathrm{C}_{6} \mathrm{H}_{4}\left(\mathrm{OC}_{2} \mathrm{H}_{5}\right)-\mathrm{CHBr}-\mathrm{CHBr}-\mathrm{CO}\left(\mathrm{OC}_{2} \mathrm{H}_{5}\right) \text {. }
$$

Theory.

Carbon ........... 41.05

Hydrogen ........... $4: 21$
Experiment.

$40 \cdot 64$

$4 \cdot 2$

This body may be called ethylic ethylorthoxyphenyldibromopropionate. It melts at $78^{\circ}$. It is rather easily soluble in hot petroleum spirit, and crystallises from it in small transparent prisms, sometimes having the appearance of hexagonal plates.

\section{Action of Alcoholic Potassic Hydrate on Ethyloxthoxyphenyldibromo- propionate.}

This substance, when mixed with cold alcoholic potassic hydrate, gives potassic bromide, and the solution is found to contain a new acid, which was separated by diluting with water and acidifying with hydrochloric acid; it was then collected and washed.

This was crystallised from boiling water in which it is difficultly soluble, and then from carbon disulphide. It gaxe on analysis the following numbers :-

0.1130 of substance gave 0.2016 of $\mathrm{CO}_{2}$, and 0.0438 of $\mathrm{OH}_{2}$.

From the percentages these numbers give it will be seen that this substance has the formula-

$$
\mathrm{C}_{11} \mathrm{H}_{11} \mathrm{BrO}_{3}=\mathrm{C}_{6} \mathrm{H}_{4} \cdot\left(\mathrm{OC}_{2} \mathrm{H}_{5}\right)-\mathrm{C}_{2} \mathrm{HBr}-\mathrm{COOH},
$$

and is therefore ethylorthoxylphenylbromacrylic acid.

Theory.

Carbon............... 48.7

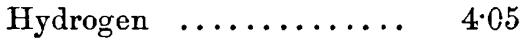

Experiment. $48 \cdot 65$ $4 \cdot 3$

This substance melts at $164^{\circ}$, and may be distilled without decomposition. It crystallises apparently in flat square prisms, the product when pressed having a satiny aspect. It is rather difficultly soluble in carbon disulphide, easily so in chloroform and in alcohol.

The oily product obtained by the action of bromine on $\beta$-ethylic ethylorthoxyphenyl acrylate, appears to yield this acid when treated with alcoholic potassic hydrate. 
When this acid is boiled with potassic hydrate, all the bromine is removed from it, and a product, which is evidently ethylorthoxyphenylpropiolic acid, is obtained: It crystallises from water very similarly to the methylic derivative already described, and with nitric acid it also gives the same coloured reaction.

\section{a-Methylorthoxyphenylacrylic Acid and Hydriodic Acid (fuming).}

The acids when left in contact for some time unite, and the product, when treated with a solution of sodic carbonate, decomposes, with the formation of orthovinylanisoill. It appeared to be exactly the same as that obtained in a similar manner from the $\beta$-acid. This was confirmed by a determination of its density.

\begin{tabular}{|c|c|c|}
\hline Produe & & From $\beta$-acid. \\
\hline Sp. gr. at $15^{\circ}$ & $1 \cdot 0093$ & $1 \cdot 0095$ \\
\hline , 30 & $1 \cdot 001$ & 1.000 \\
\hline
\end{tabular}

a- and $\beta$-Methylorthoxylphenylacrylic Acid and Hypochlorous Acid.

On passing chlorine into a solution of these acids in sodic carbonate, they behave exactly alike. The solutions become turbid, and an oil gradually accumulates, and is the principal product of the reaction. It was purified and analysed, but was not a definite body, the numbers seeming to show that it was composed of mono- and dichlor-orthovinylanisoill. A small quantity of a gummy acid was obtained from the aqueous solution, but in too small a quantity to admit of examination.

\section{Products Derived from Propionic Coumarin.}

\section{Methylic-a-Methylorthoxyphenylcrotonate.}

As I have previously shown propionic coumarin behaves like the ordinary one with caustic alkalies, forming saline compounds, which when treated with acids decompose with regeneration of the propionic coumarin. A quantity of the sodic compound of this conmarin was treated with methyl iodide in order to obtain a compound corresponding to $\alpha$-methylorthoxyphenylacrylic acid. The proportions used were 10 of propionic coumarin, 5 of pure sodic hydrate, and 18 of methylic iodide. The propionic coumarin was first boiled with water and the sodic hydrate until dissolved, the resulting solution concentrated, mixed with alcohol and the methylic iodide, and then heated to $100^{\circ}$ in a soda-water bottle securely corked for three or four hours. The alcohol was distilled off, water and ether added to facilitate the separation of the sodic jodide from the oily product which had been formed. The ethereal solution was then agitated with a solution of 
sodic carbonate, which remores a small quantity of the new acid held in solution by the ether. It was then separated, dried over potassic carbonate, and distilled.

After the ether had passed over, the temperature rapidly increased until it reached $274-275^{\circ}$, when it remained constant for some time ; it then rapidly rose, owing to the presence of some unchanged propiouic coumarin. This is always present to some extent, even in the latter part of the fraction boiling within the above limits; and after a number of combustions had been made, it was found that only the early portions of the distillate were sufficiently pure to give good numbers, a very small quantity of propionic coumarin moking a considerable difference in the percentage composition. The following are some of the results obtained on its analysis :-

I. 0.1196 of substance gare 0.3060 of $\mathrm{CO}_{2}$, and 0.0726 of $\mathrm{OH}_{2}$.

II. 0.1165 of substance gave 0.2968 of $\mathrm{CO}_{2}$, and 0.0715 of $\mathrm{OH}_{2}$.

III. 0.1181 of substance gave 0.3018 of $\mathrm{CO}_{2}$, and 0.0725 of $\mathrm{OH}_{2}$.

These numbers give percentages agreeing with those required by the formala-

$$
\begin{array}{r}
\mathrm{C}_{12} \mathrm{H}_{14} \mathrm{O}_{3}=\mathrm{C}_{6} \mathrm{H}_{4}\left(\mathrm{OCH}_{3}\right)-\mathrm{C}_{3} \mathrm{H}_{4}-\mathrm{CO}\left(\mathrm{OCH}_{3}\right) . \\
\text { Experiment. }
\end{array}
$$

\begin{tabular}{|c|c|c|c|c|}
\hline & & & & \\
\hline \multicolumn{2}{|l|}{ Theory. } & I. & II. & III. \\
\hline Hrdrocen & 6.79 & 6.75 & 6.82 & 6.82 \\
\hline
\end{tabular}

This substance is therefore the methylic ether of an $\alpha$-methylorthoxyphenylcrotonic acid, and may be called methylic-a-methylorthoxyphenylcrotonate.

This compound is a thick, colourless, highly refracting fluid. Its sp. gr. compared with water at the same temperatures is-

$$
\text { at } 15^{\circ} \ldots .1 \cdot 1112 \text { at } 30^{\circ} \ldots .1 \cdot 1061
$$

The boiling point is $274-275^{\circ}$, and its magnetic rotary power for the sodium line $2 \cdot 232$, water $=1$; both of these are probably a little high from the presence of minute quantities of propionic coumarin in the substance used.

It does not appear to be easily changed into its isomeride by boiling. It dissolves in sulphuric acid with evolution of heat, and on diluting the mixture propionic coumarin separates out. Its isomeride, the B-ether, changes under these circumstances to a very thick oil, apparently in consequence of polymerisation. 


\section{a-Methylorthoxyphenylerotonic Acid.}

To obtain the acid from its methylic derivative, it was boiled with alcoholic potassic hydrate until quite miscible with water. This decomposition takes place easily. Water was then added, and the solution boiled until free from alcohol, and on being acidified with hydrochloric acid an oily acid separated, which soon solidified to a crystalline mass. This was collected, washed, dried between bibulous paper, and crystallised from petroleum spirit. It was then obtained in brittle feathery crystals. For further purification it was recrystallised from alcohol. The analysis of this body gave the following numbers :-

I. 0.2615 of substance gave 0.6564 of $\mathrm{CO}_{2}$, and 0.1472 of $\mathrm{OH}_{2}$. II. 0.2492 of substance gave 0.6276 of $\mathrm{CO}_{2}$, and 0.1424 of $\mathrm{OH}_{2}$.

These give percentages agreeing with the formula-

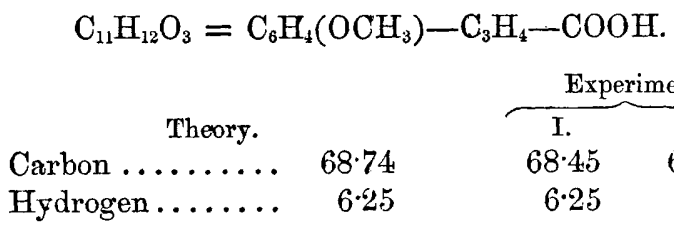

$\begin{array}{cr}\text { II. } & \text { II. } \\ 68.45 & 68.68 \\ 6.25 & 6.34\end{array}$

This acid may therefore be called a-methylorthoxyphenylcrotonic acid. It melts at $118^{\circ}$, whereas the $\beta$-acid melts at $107^{\circ}$. It does not appear to be converted into the $\beta$-acid by the action of light. It is freely soluble in alcohol, from which it separates in brilliant crystals, belonging to the oblique system. These have been measured, and are described at the end of this paper (p.449). It is moderately soluble in hot petroleum spirit. It has no rery decided taste at first, bat after being in the mouth for some time, it produces a sensation of sweetness, continuing for a long time, and causing a flow of saliva.

With phosphoric chloride it yields propionic coumarin. The reaction may be written thus:-

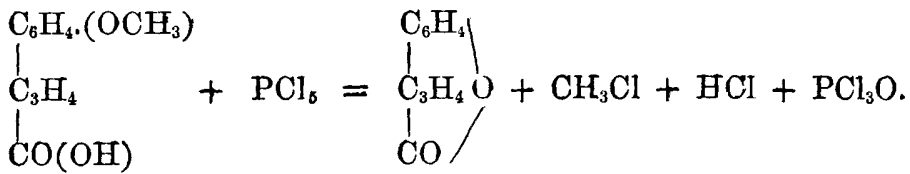

When dissolved in concentrated sulphuric acid, it decomposes with formation of propionic coumarin.

The following comparison of the properties of the normal acid obtained from the hydride of methyl salicyl and propionic anhydride, now called $\beta$-methylorthoxyphenylcrotonic acid, and the $\alpha$-acid from 
propionic coumarin will show how greatly they differ from each other :-

\begin{tabular}{|c|c|c|}
\hline & $\alpha$-Acid. & $\beta$-Acid. \\
\hline Melting point............ & $118^{\circ}$. & $107^{\circ}$. \\
\hline Colour of ferrie salt $\ldots \ldots$ & $\begin{array}{l}\text { A somewhat reddish-buff } \\
\text { amorphous precipitate. }\end{array}$ & $\begin{array}{l}\text { A yellowish-buff precipi- } \\
\text { trte. }\end{array}$ \\
\hline Colour of cupric salt...... & $\begin{array}{l}\text { A pale bright yellow-green } \\
\text { precipitate. }\end{array}$ & $\begin{array}{l}\text { A pale bright blue precipi- } \\
\text { tate. }\end{array}$ \\
\hline Silver salt $\ldots \ldots \ldots \ldots \ldots$ & $\begin{array}{l}\text { A white precipitate, be- } \\
\text { coming crystalline in a } \\
\text { short time. }\end{array}$ & A white precipitate. \\
\hline Sodium salt............ & Deliquescent. & Not deliquescent. \\
\hline Barium salt $\ldots \ldots \ldots \ldots$ & $\begin{array}{l}\text { Extremely soluble and } \\
\text { drying up to an amor- } \\
\text { phous product. }\end{array}$ & $\begin{array}{l}\text { Rather easily soluble in } \\
\text { boiling water, but de- } \\
\text { posited, on cooling, in } \\
\text { beautiful masses of fine } \\
\text { needles, which when dry } \\
\text { appear like asbestos. }\end{array}$ \\
\hline With $\mathrm{PCl}_{5} \ldots \ldots \ldots \ldots$ & Yields propionic coumarin. & $\begin{array}{l}\text { Yields the chloride of the } \\
\text { acid radical. }\end{array}$ \\
\hline With $\mathrm{H}_{2} \mathrm{SO}_{4} \ldots \ldots \ldots \ldots$ & Yields propionic couınarin. & $\begin{array}{l}\text { Yields an apparently poly- } \\
\text { merised acid. }\end{array}$ \\
\hline
\end{tabular}

a-Methylorthoxyphenylcrotonie acid when boiled with dilute hydrochloric acid for some time, decomposes, yielding an amorphous resinous product and an acid forming a soluble barium salt, but apparently not the $\beta$-acid.

With nitric acid both the $\alpha$ - and $\beta$-acids yield compounds giving bright red colours with alcoholic potassic hydrate.

\section{$\alpha$ - and $\beta$-Methylorthoxyphenylcrotonic Acids and Nascent Hydrogen.}

On placing sodium-amalgam in solutions of the sodium salts of these acids, scarcely any hydrogen is given off for an hour or more, or until the reaction is practically over. On acidifying the solutions, oily products separate in both cases, gradually solidifying and becoming crystalline.

They were separately converted into baric salts and twice crystallised. They had exactly the same appearance, were easily soluble in water, and appeared to contain water of crystallisation.

These salts were dissolved in water and decomposed with hydrochloric acid, and the acids crystallised from petroleum spirit. They 
melted at the same temperature, and were evidently identical. Submitted to combustion, they gave the following numbers :-

I. 0.1517 of substance gave 0.3793 of $\mathrm{CO}_{2}$, and $0 \cdot 1028$ of $\mathrm{OH}_{2}$. II. 0.2386 of substance gave 0.5929 of $\mathrm{CO}_{2}$, and 0.1498 of $\mathrm{OH}_{2}$. III. 0.1111 of substance gave 0.2765 of $\mathrm{CO}_{2}$, and 0.0726 of $\mathrm{OH}_{2}$.

The substance used in analysis I was prepared from the $\beta$-acid, that from II and III from the $\alpha$-acid.

These numbers give percentages agreeing with those required by the formula-

$$
\mathrm{C}_{11} \mathrm{H}_{14} \mathrm{O}_{3}=\mathrm{C}_{6} \mathrm{H}_{4}\left(\mathrm{OCH}_{3}\right)-\mathrm{C}_{3} \mathrm{H}_{6}-\mathrm{COOH} \text {. }
$$

\begin{tabular}{crrrr} 
& & \multicolumn{3}{c}{ Experiment. } \\
\cline { 3 - 5 } Theory. & & \multicolumn{1}{c}{ I. } & II. & III. \\
Carbon...... & 68.04 & $68 \cdot 18$ & $67 \cdot 80$ & $67 \cdot 88$ \\
Hydrogen.... & $7 \cdot 20$ & $7 \cdot 20$ & 6.97 & $7 \cdot 26$
\end{tabular}

The acid is therefore dihydromethylorthoxyphenylcrotonic or methylorthoxyphenylbutyric acid. It melts at 55-56 . When strongly heated it distils, with but little decomposition, coming over as a colourless oil, which gradually solidifies to a crystalline mass on standing. It is extremely soluble in alcohol, carbon disulphide, and glacial acetic acid. From boiling petroleum spirit it gradually crystallises as it cools, usually in a confused state, but sometimes in transparent prisms. It is soluble to a small extent in boiling water, the solution becoming milky on cooling, but it separates out after standing in long transparent needles.

Baric Salt.-This was obtained by boiling the acid with a solution of baric hydrate, removing the excess of the latter with carbonic acid, boiling, filtering, and then evaporating the filtrate to a small bulk. The baric salt then came down in small transparent plates, which when seen under the microscope were somewhat like crystals of baric chloride; they also showed a fine play of colours with polarised light. It contains water of crystallisation, which is driven off at $100^{\circ}$

0.1962 of substance dried at $100^{\circ}$ gave 0.0867 of $\mathrm{BaSO}_{4}=25.98$ per cent. Ba.

The formula $\mathrm{C}_{22} \mathrm{H}_{26} \mathrm{BaO}_{6}$ requires 26.29 per cent. $\mathrm{Ba}$.

It is moderately soluble in cold and easily in boiling water. With silver nitrate it gives a white apparently amorphous precipitate of the silver salt.

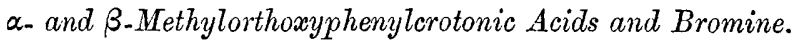

Separate quantities of these two acids were finely powdered and exposed to the vapour of bromine in the dark for about 36 hours. Hydrobromic acid was formed, and the products after being kept VOL. XXXIX. 
over potassic hydrate for some days, were found to have increased in weight, and become about two and a half times as heavy as they were originally. They were twice crystallised from chloroform, and thus obtained as a white crystalline powder. The products were identical, and gave the following numbers on analysis :-

I. 0.2030 of substance gave 0.1956 of $\mathrm{CO}_{2}$, and 0.0374 of $\mathrm{OH}_{2}$.

II. 0.2098 of substance gave 0.1955 of $\mathrm{CO}_{2}$, and 0.0387 of $\mathrm{OH}_{2}$.

III. 0.1624 of substance gave 0.1533 of $\mathrm{CO}_{2}$, and 0.0296 of $\mathrm{OH}_{2}$.

Nos. I and II were made from $\beta$-acid, No. III from $\alpha$-acid. The percentages yield numbers leading to the formula-

$$
\mathrm{C}_{11} \mathrm{H}_{10} \mathrm{Br}_{4} \mathrm{O}_{3} \text {. }
$$

\begin{tabular}{|c|c|c|c|c|}
\hline \multicolumn{5}{|c|}{$\mathrm{C}_{11} \mathrm{H}_{10} \mathrm{Br}_{4} \mathrm{O}_{3}$} \\
\hline Theory. & \multirow[b]{2}{*}{$25 \cdot 88$} & I. & II. & III. \\
\hline Carbon...... & & $26 \cdot 23$ & $25 \cdot 41$ & $25 \cdot 74$ \\
\hline Hydrogen.... & 1.96 & $2 \cdot 04$ & $2 \cdot 04$ & $2 \cdot 02$ \\
\hline
\end{tabular}

This substance may be called dibromide of dibromomethylorthoxyphenylcrotonic acid or tetrabromomethylorthoxyphenylbutyric acid. It melts at about $200^{\circ}$. It is moderately soluble in boiling but only a little so in cold chloroform. In alcohol it is easily soluble, but evidently decomposes as the fluid becomes acid. It gradually decomposes when boiled with water.

It is not dissolved by cold aqueous ammonia, or only to a small extent, but it becomes more crystalline, apparently in consequence of the formation of an ammonia salt, and not of any decomposition, for if the mixture be acidulated with nitric acid and filtered, the filtrate is found to contain only a trace of bromine. If heat, however, be employed, the ammonium then attacks it, and a milky fluid results.

If left in contact with a 50 per cent. solution of pure sodic hydrate in the cold, it appears to be but little acted upon, very little bromine being removed, but if the mixture be diluted so as to form a clear solution, and then gradually warmed at about $40-45^{\circ}$, it begins to become milky.

Endeavours have been made to obtain dibromides of the $\alpha$ - and $\beta$-acids, and also their ethers, but no definite products have as yet been obtained. The constitution of this body is probably-

$$
\mathrm{C}_{6} \mathrm{H}_{2} \mathrm{Br}_{2}\left(\mathrm{OCH}_{3}\right)-\mathrm{CHBr}-\overparen{\mathrm{CBr}-\mathrm{COOH}}
$$

a-Methylorthoxyphenylcrotonic Acid and Hydriodic Acid (fuming).

This acid combines with hydriodic acid, sp. gr. 1.94, just as the $\beta$-acid does (Chem. Soc. J., May, 1878), and the product, when treated 
with sodic carbonate, yields orthoallylanisoïl, boiling at $222-223^{\circ}$, and having the sp. gr. at $30^{\circ}$ of 0.989 , numbers showing its identity' with the product obtained from the $\beta$-acid.

\section{$\boldsymbol{\beta}$-Methylorthoxylphenylcrotonate of Methyl.}

This body was prepared for the purpose of comparing it with its isomeride the $\alpha$-product. It was made by converting the $\beta$-acid intc its chloride with phosphoric chloride, and then gradually adding it to methylic alcohol. It was well washed with water, and then a little alkali, and afterwards dried and distilled, when most of it came over at $286^{\circ}$. On analysis it gave the following numbers :-

0.1462 of substance gave 0.3738 of $\mathrm{CO}_{2}$, and 0.0898 of $\mathrm{OH}_{2}$.

\begin{tabular}{ccc} 
Theory. & \multicolumn{1}{c}{$\begin{array}{c}\text { Experiment. } \\
\text { Carbon................ }\end{array} 69 \cdot 9 \cdot 72$} \\
Hydrogen........... & $6 \cdot 79$ & $6: 82$
\end{tabular}

This ether is very like its isomeride, being a thick, highly refracting oil, its boiling point is, however, about $11^{\circ}$ higher; it is also more dense, its specific gravity compared with water at same temperatures being-

$$
\begin{array}{ll}
\text { at } 15^{\circ} \ldots \ldots \ldots \ldots & 1 \cdot 1279 \\
\text { at } 30^{\circ} \ldots \ldots \ldots \ldots & 1 \cdot 1136
\end{array}
$$

\section{Products derived from Butyric Coumaria.}

\section{Methylic $\alpha$-Methylorthoxyphenylangelate.}

Butyric coumarin was converted into the saline sodic derivative, and the compound treated with methylic iodide, as in the preparation of the analogous compounds from propionic coumarin, the proportion being varied to suit the different atomic weight of the body. In this manner a methylic ether was obtained, which on analysis gave the following numbers:-

I. 0.1446 of substance gave 0.3755 of $\mathrm{CO}_{2}$, and 0.0932 of $\mathrm{OH}_{2}$. II. 0.1117 of substance gave 0.2896 of $\mathrm{CO}_{2}$, and 0.0704 of $\mathrm{OH}_{2}$.

From these results it is seen to have the formula-

$$
\mathrm{C}_{13} \mathrm{H}_{18} \mathrm{O}_{3}=\mathrm{C}_{6} \mathrm{H}_{4}\left(\mathrm{OCH}_{3}\right) \cdot \mathrm{C}_{4} \mathrm{H}_{6} \cdot \mathrm{CO}\left(\mathrm{OCH}_{3}\right) \text {. }
$$

\begin{tabular}{ccrr} 
Theory. & & \multicolumn{2}{c}{ Experiment. } \\
\cline { 2 - 3 } Carbon ............ & 70.9 & 70.81 & 70.7 \\
Hydrogen.......... & 7.27 & 7.23 & 7.0
\end{tabular}

It may therefore bo called methylic a-methylorthoxyphenylangelate. 
It is a thick, colourless, highly refracting fluid, boiling at $282^{\circ}$, and having a density of-

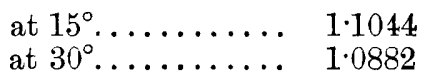

compared with water at the same temperatures. With concentrated sulphuric acid it decomposes with formation of butyric coumarin.

\section{a-Methylorthoxyphenylangelic Acid.}

The methylic ether just described is easily decomposed by boiling with an alcoholic solution of potash. The separatiou of the acid from the resulting potassium salt and its purification were performed in exactly the same way as in the case of the preparation of $\alpha$-methylorthoxyphenylcrotonic acid.

On analysis it gave the following numbers:-

I. 0.2459 of substance gave 0.6325 of $\mathrm{CO}_{2}$, and 0.1498 of $\mathrm{OH}_{2}$.

II. 0.2556 of substance gave 0.6551 of $\mathrm{CO}_{2}$, and 0.1544 of $\mathrm{OH}_{2}$.

These numbers gives percentages leading to the formula-

$$
\mathrm{C}_{12} \mathrm{H}_{14} \mathrm{O}_{3}=\mathrm{C}_{6} \mathrm{H}_{4}\left(\mathrm{OCH}_{3}\right) \cdot \mathrm{C}_{4} \mathrm{H}_{6}-\mathrm{COOH} \text {. }
$$

\begin{tabular}{ccccr} 
Theory. & & \multicolumn{3}{c}{ Experiment. } \\
Carbon $\ldots \ldots \ldots \ldots$ & 69.9 & 70.1 & II. \\
Hydrogen $\ldots \ldots \ldots$ & 6.79 & 6.77 & 6.71
\end{tabular}

This may be called $\alpha$-methylorthoxylphenylangelic acid. It melts at $88^{\circ}$. It is very easily soluble in alcohol, and crystallises from it after standing for some time in very beautiful transparent crystals. These have been examined, and are described at the end of this paper (p. 451). It is moderately soluble in boiling petroleum spirit. When tasted it produces the same effect of sweetness as the $\alpha$-methylorthoxyphenylcrotonic acid, but not so distinctly.

With phosphoric chloride it yields butyric coumarin, thus:-

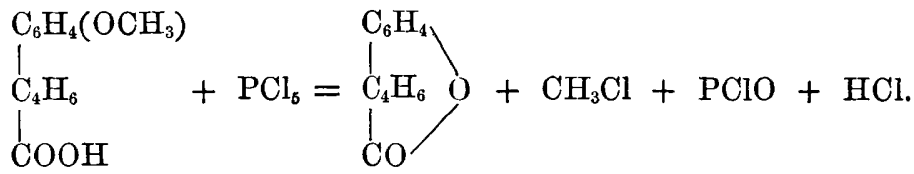

With concentrated sulphuric acid it decomposes, with formation of butyric coumarin.

The following comparison of its properties with those of its isomeride obtained from the hydride of methylsalicyl and butyric anhydride, now called $\beta$-methylorthoxyphenylangelic acid, will show how much they differ from each other :- 


\begin{tabular}{|c|c|c|}
\hline & $a$-Acid. & $\beta$-Acid. \\
\hline Melting point........... & $88^{\circ}$ & $105^{\circ}$ \\
\hline Colour of ferric salt ...... & Orange-brown. & Buff. \\
\hline Colour of cupric salt...... & A bright yellow-green. & Pale blue-green. \\
\hline Silver salt $\ldots \ldots \ldots \ldots \ldots$ & $\begin{array}{l}\text { A white precipitate, be- } \\
\text { coming erystalline; solu- } \\
\text { ble in hot water, and } \\
\text { separating in nadular } \\
\text { masses of crystals on } \\
\text { cooling. }\end{array}$ & $\begin{array}{l}\text { An amorphous precipitate, } \\
\text { soluble in boiling water, } \\
\text { and deposited in an amor- } \\
\text { phous state on cooling. }\end{array}$ \\
\hline Barium salt ........... & Very soluble in water. & $\begin{array}{l}\text { Much less soluble than the } \\
\alpha \text {-salt. }\end{array}$ \\
\hline
\end{tabular}

$\alpha-$ and $\beta$-Methylorthoxyphenylangelic Acids and Bromine.

Specimens of these acids were exposed to the action of bromine vapour in the dark for about 24 hours ; they became sticky products, containing much free bromine. To remove this from them, they were kept over solid potassic hydrate, a few days after which they became much harder, and capable of being broken up. After this had been done they were again left over potassic hydrate for several days. They were then boiled with sufficient petrolenm spirit (b. p. $100-130^{\circ}$ ) to dissolve them, filtered, and the solution allowed to stand. Crystalline products were deposited, and on analysis gave the following numbers :-

I. $0 \cdot 1589$ of substance gave $0 \cdot 1591$ of $\mathrm{CO}_{2}$, and 0.0330 of $\mathrm{OH}_{2}$.

II. $0 \cdot 1540$ of substance gave 0.1558 of $\mathrm{CO}_{2}$, and 0.0352 of $\mathrm{OH}_{2}$.

These lead to the formula-

$$
\mathrm{C}_{12} \mathrm{H}_{12} \mathrm{Br}_{4} \mathrm{O}_{3} \text {. }
$$

\begin{tabular}{cccr}
\multicolumn{3}{c}{$\mathrm{C}_{12} \mathrm{H}_{12} \mathrm{Br}_{4} \mathrm{O}_{3}}$. & \multicolumn{2}{c}{ Experiment. } \\
\cline { 2 - 2 } & & I. & \multicolumn{1}{c}{ II. } \\
Carbon $\ldots \ldots \ldots \ldots$ & $27 \cdot 4$ & $27 \cdot 18$ & $27 \cdot 58$ \\
Hydrogen $\ldots \ldots \ldots$ & $2 \cdot 29$ & $2 \cdot 30$ & $2 \cdot 54$
\end{tabular}

The substance used in No. I was made from the $\beta$-acid, No. II from the $\alpha$-acid. Both products are identical, although the crude substance obtained from the $\beta$-acid was easiest to purify, as it crystallised more freely.

This substance is the dibromide of dibromomethylorthoxyphenylangelic acid, or tetrabromomethylorthoxyphenylvaleric acid. It melts at about $159^{\circ}$, with decomposition. It is difficultly soluble in boiling 
petroleum, and nearly insoluble in it when cold. It is deposited from it in minute transparent prisms.

Its constitution is probably-

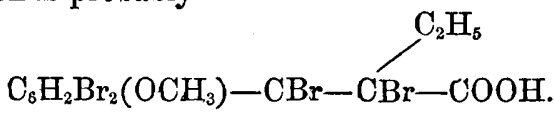

a- and B-Methylorthoxyphenylangelic Acids and Nascent Hydrogen.

Both these acids, when treated with sodium-amalgam, give a thick oily acid, which I have not been able to obtain in a fit state for analysis. It distils with but little decomposition. It gives a barium salt, forming minute crystals, very easily soluble in water. On analysis this gave $25 \cdot 17$ per cent. barium, theory requiring $24 \cdot 86$ for the formula $\mathrm{C}_{24} \mathrm{H}_{30} \mathrm{BaO}_{6}$.

\section{Methylic $\beta$-Methylorthoxyphenylangelate.}

This ether was made by treating the chloride of the acid radical with methylic alcohol. It was not analysed. It is a thick, highly refracting oil, boiling at $292^{\circ}$, and having a density of -

$$
\begin{array}{ll}
\text { at } 15^{\circ} \ldots \ldots \ldots \ldots & 1 \cdot 1100 \\
\text { at } 30^{\circ} \ldots \ldots \ldots \ldots & 1 \cdot 1008
\end{array}
$$

The boiling point is therefore about $10^{\circ}$ higher than that of the $\alpha$-isomer; it is also more dense.

\section{B-Ethylorthoxyphenylcrotonic Acid.}

The preparation of this acid was undertaken for the purpose of making some comparisons between it and its isomerides. It was prepared from the hydride of ethyl-salicyl propionic anhydride and sodic propionate in the usual manner. These materials give a very good yield of this new acid. It was purified by crystallisation from alcohol, and gave the following numbers on analysis :-

I. 0.1781 of substance gave 0.4541 of $\mathrm{CO}_{2}$, and 0.1084 of $\mathrm{OH}_{2}$. II. 0.1574 of substance gave 0.4030 of $\mathrm{CO}_{2}$, and 0.0966 of $\mathrm{OH}_{2}$.

These numbers give percentages agreeing with the formula-

$$
\mathrm{C}_{12} \mathrm{H}_{14} \mathrm{O}_{3}=\mathrm{C}_{6} \mathrm{H}_{4}\left(\mathrm{OC}_{2} \mathrm{H}_{5}\right)-\mathrm{C}_{3} \mathrm{H}_{4}-\mathrm{CO}(\mathrm{OH}) \text {. }
$$

Theory.

Carbon ........ $69 \cdot 9$

Hydrogen....... 6.79
Experiment.

\begin{tabular}{rr}
\hline I. & II. \\
69.53 & $69 \cdot 85$ \\
6.76 & 6.81
\end{tabular}


B-Ethylorthoxyphenylcrotonic acid melts at $133^{\circ}$. It is a beautiful acid, and crystallises in rather large tables or flat prisms, apparently right rhombic. It is easily soluble in alcohol.

Baric Salt. - On adding baric chloride to a hot solution of the ammonic salt of this acid, no precipitate forms, but on concentrating the baric salt separates out as thick oily drops; on cooling, however, the solution becomes filled with beantifully white satiny needles of this compound, not unlike benzoic acid ; on adding these crystals to boiling water they partially dissolve and partially fuse. It is moderately soluble in cold, and rather easily so in boiling water. Sodic chloride precipitates it from its aqueous solution.

\section{Methylic Methylparoxyphenylacrylate.}

This substance was prepared for the purpose of comparing its boiling point with its isomerides. For this purpose methylparoxyphenylacrylic acid was treated with pentachloride of phosphorus, and the resulting chloride gradually added to methylic alcohol. After the reaction was over, the product on standing a short time began to deposit this ether in beautiful white plates. It was purified by recrystallisation from alcohol, and on analysis gave the following numbers :-

0.0958 of substance gave 0.2422 of $\mathrm{CO}_{2}$, and 0.0549 of $\mathrm{OH}_{2}$.

\begin{tabular}{ccc} 
Theory. & \multicolumn{1}{c}{ Experiment. } \\
Carbon $\ldots \ldots \ldots \ldots \ldots$ & $68 \cdot 75$ & 68.95 \\
Hydrogen $\ldots \ldots \ldots \ldots$ & $6 \cdot 25$ & 6.26
\end{tabular}

I 'ethylparoxyphenylacrylate of methyl melts at $89^{\circ}$, and on cooling soli ifies to a beautiful hard crystalline mass. It distils at $303^{\circ}$. It is easi y soluble in boiling, and only moderately so in cold alcohol. It crystallises in rather large, irregular plates, very smooth to the touch. It will be observed that its boiling point is about $10^{\circ}$ higher than its $\beta$-ortho isomeride.

\section{Coumarins.}

The following are the observed boiling points of these bodies made under the same conditions:---

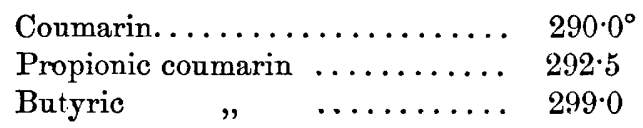

The crystalline forms of the two last coumarins have been determined, and will be found at the end of this paper (pp. 446, 447).

Dr. Gladstone has been good enough to determine the refraction 
equivalent of ordinary coumarin for me, and obtained the following results :-

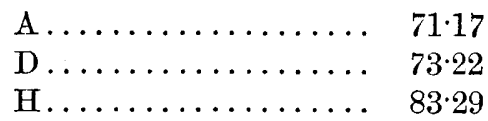

A solution of ordinary coumarin in sodic hydrate (i.e., $\alpha$-sodic coumarate) when exposed to sunlight for some weeks, is partially changed, and when acidified gives coumarin mixed with about its own weight of $\beta$ or ordinary coumaric acid, judging from its fusing point, \&c.

From the foregoing results we see that acids isomeric with the already known methylorthoxylphenylcrotonic and angelic acids can be obtained from propionic and butyric coumarins, in the same way as a-methylorthoxyphenylacrylic acid is obtained from ordinary coumarin. These new $\alpha$-acids, as I have called them, differ in a very marked way from the corresponding ordinary or $\beta$-acids, as the comparisons given in this paper show. They are, however, not so susceptible of change as the first member of the series, viz., $\alpha$-methylorthoxyphenylacrylic acid, which, by the action of heat or light, soon becomes converted into the $\beta$-acid. This change I have not hitherto been able to effect with these two new acids, probably because I have not given sufficient time. There is also less difference between the boiling points of their methylic ethers and those of the $\beta$-acids, than between those of the $\alpha$ - and $\beta$-methylorthoxyphenylacrylic acids. This greater readiness to change, and wider difference of properties, as compared with their homologues, is apparently common to acrylic compounds. The hydrocarbons and anisoills related to them as cinnamene, isopropylvinylbenzene, para- and ortho-vinyl anisoill, also rapidly polymerise wheu exposed to the action of heat or light, their homologues not doing so, or only slowly, except when submitted to the action of chemical agents, such as sulphuric acid. The difference between their boiling points and that of their next homologue is also much greater than between the homologues above them, so that it is not surprising to find that $\alpha$-methylorthoxyphenylacrylic acid should exhibit differences from the $\beta$-acid more marked than its homologues; but from the manner of formation of these acids from their coumarins, as well as from their properties, there cannot be any doubt that the isomerism existing between them and the corresponding $\beta$-acids is of the same kind as that between the $\alpha$ - and $\beta$-acrylic acids.

From the results which have been obtained, it appears generally that the effect of chemical action (unless of a feeble kind) on any part of a-methylorthoxyphenylacrylic acid or its homologues, is the formation of a $\beta$-compound or its derivatives. Thus, fuming nitric acid acting on the $\mathrm{C}_{6}$-group of the acrylic acid converts it into a 
$\beta$-dinitro-acid. Phosphorus pentachloride acting on the carboxyl group produces the chloride of the $\beta$-acid. Nascent hydrogen acting upon the $\mathrm{C}_{2} \mathrm{H}_{2}$, or analogous groups in the homologous acids, gives the same hydro-acids as the $\beta$-acids. Bromine in excess, acting on the $\mathrm{C}_{6}$ and $\mathrm{C}_{2} \mathrm{H}_{2}$ or analogous groups, also gives the same product as the $\beta$-acid under similar circumstances. The explanation of this would appear to be that the heat evolved by the chemical action converted the $\alpha$-into the $\beta$-derivative.

If, however, $\alpha$-methylorthoxyphenylacrylic acid dissolved in chloroform or carbon disulphide be treated with a limited amount of bromine, a dibromide is obtained isomeric with the one produced from the $\beta$-acid nnder similar circumstances.*

The formation of these two compounds corresponds with the formation of the dibromides of maleic and fumaric acid, the bromine being connected with $\mathrm{C}_{2} \mathrm{H}_{2}$ in both cases, so that any argument based upon the one set of dibromo-compounds applies to the other. $\dagger$

As maleic acid forms a dibromide different from that of fumaric acid, it is supposed that their isomerism rests on the $-\mathrm{C}_{2} \mathrm{H}_{2}-$ group, the arrangement of its elements in maleic acid being $-\mathrm{CH}_{2}-\stackrel{\text { C }}{-}$, and in fumaric $-\mathrm{CH}=\mathrm{CH}$-, so that the dibromides would contain respectively $-\mathrm{CH}_{2}-\mathrm{CBr}_{2}-$ and $-\mathrm{CHBr}-\mathrm{CHBr}-$. Anschütz (Ber., 10, 1886) thinks that this order should be reversed.

But it is obvious that the fact of these acids forming isomeric dibromides does not necessarily require this explanation, as the dibromides may be isomeric simply because the acids themselves are so. Probably the amount of heat given out in their formation is not sufficient to change the maleic into a fumaric compound.

The hypothesis that the isomerism of these acids is dependent upon the two different arrangements in the $\mathrm{C}_{2} \mathrm{H}_{2}$ group is very difficult to accept, because it requires that its structure should change in opposite ways under the same influence. If a body contained the unsymmetrical group $-\mathrm{CH}_{3}-\mathrm{I}-\mathrm{C}-$ it would not be difficult to conceive that by the action of heat it might become symmetrical by changing into - $\mathrm{CH}=\mathrm{CH}-$, but that this group should by the very same influence turn back again to $-\mathrm{CH}_{2}-\mathrm{C}$ - is very incomprehensible; but this view of the subject I think requires this to be believed, becanse maleic acid when heated is converted into fumaric acid, and this on further heating changes back, maleic anhydride and water being formed.

* In this reaction the amount of heat given out is very small compared with that given out when the acid is treated with nascent hydrogen from sodium amalgam.

+ Baeyer has also referred to the isomerism of these acids as having a great resemblance to that existing between fumaric and maleic acids. 
If we consider the relationship of ordinary, or as I for distinction sake will call it, $\beta$-coumaric, acid to the one obtained from coumarin, which I propose to call $\alpha$-coumaric acid, the compounds of which were examined by R. Williamson (Chem. Soc. J., 1875, 850), we find that the same or analogous changes take place by the action of heat on them.

When $\beta$-coumaric acid, or which is practically the same, acetocoumaric acid* is heated, it splits up into coumarin and acetic acid, thus :-

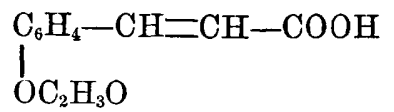

Aceto-coumaric acid.

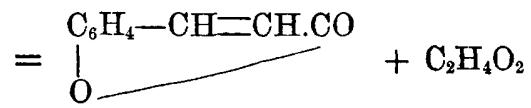

Coumarin.

In this decomposition we do not see anything to warrant us in supposing that the - $\mathrm{CH}=\mathrm{CH}-$ group has changed, as it has had no part to play in the decomposition, and it is scarcely conceivable that it should have become unsymmetrical by the action of heat alone; but even supposing it had, and the constitution of coumarin thus became-

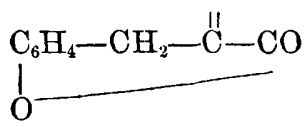

the $\alpha$-coumarate would then be represented thus-<smiles>[R20]CCC(=O)O[R]</smiles>

and on submitting this to heat, the very agent which previously was supposed to have changed the $-\mathrm{CH}-\mathrm{CH}-$ into $-\mathrm{CH}_{2}-\stackrel{\text { CH}}{-}$, now makes it do the reverse, and by converting it into a $\beta$-coumarate, become again $-\mathrm{CH}=\mathrm{CH}-$.

From these considerations I do not think that this isomerism can be accounted for by this change of structure in the $\mathrm{C}_{2} \mathrm{H}_{2}$ group, nor do I see any other evidence of weight to support it. If this be so, and there is evidently no ground for supposing that any change of arrangement takes place in the other groups of which these bodies are constituted, then this isomerism cannot be explained by any ordinary kind of chemical constitutional formula we have at present. $\dagger$

* The reason why aceto-coumaric acid yields coumarin, and coumaric acid does not, is, I believe, due to the phenolic hydrogen being replaced by acetyl, and thus keeping the decomposition to a single molecule of the acid, coumaric acid being so ready to form complex resinous products.

+ By Van't Hoff's hypothesis it is possible to represent coumaric acid in two different ways. This, however, also refers to the $\mathrm{C}_{2} \mathrm{H}_{2}$ group. 
This being the case, it will be interesting to refer to the physical facts for information, and see in which particulars these isomeric bodies differ from each other.

The following is a table showing the observed boiling points, which were all made in the same apparatus and with the same thermometer; also the specific gravities of the ethers of the acids described in this paper.

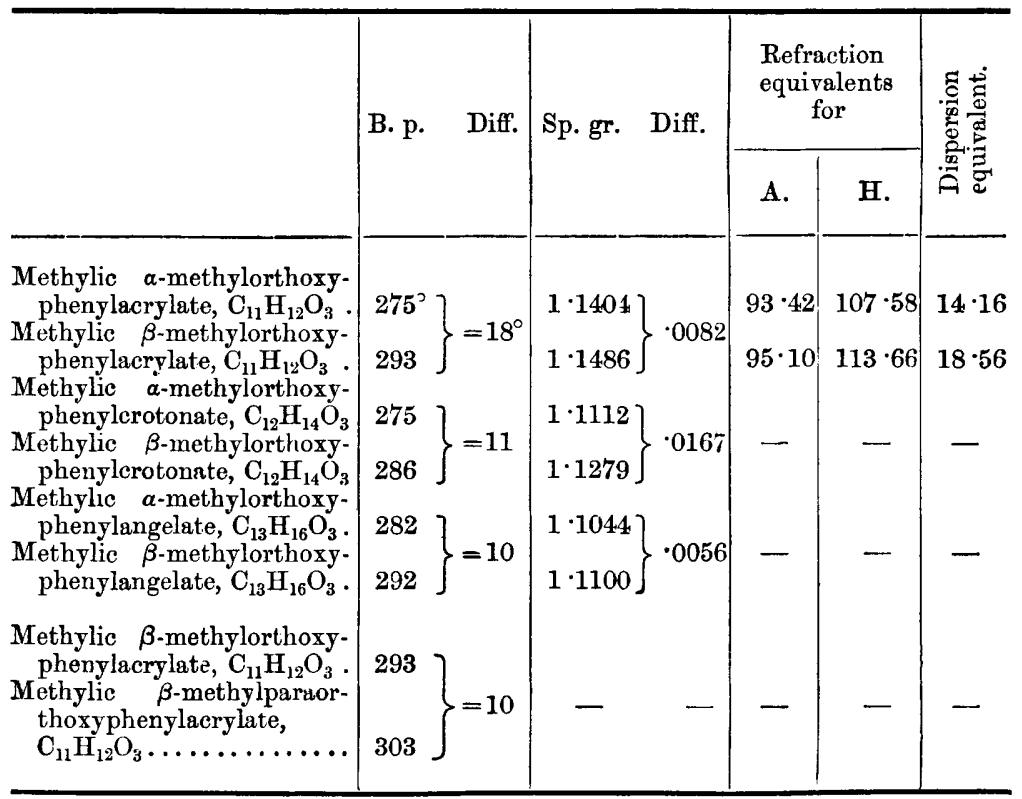

From this we see that the difference between the boiling points of the $\alpha$ - and $\beta$-methylic ethers is very large, in the case of the first member of the series no less than $18^{\circ}$, and in the other instances $10^{\circ}$ and $11^{\circ}$, an amount as great as that between the $\beta$-ortho- and paramethylic ethers given at the bottom of the table. The boiling points of the $\alpha$-compounds it will be observed are always the lowest.

If we compare the densities, we invariably find the $\alpha$-products to be lower than the $\beta$. This difference is probably somewhat greater than the determinations indicate, for in the case of methylic $\alpha$-methylorthoxyphenylacrylate, there is a certain amount of the $\beta$-ether produced when it is rectified to remove impurities; it is also likely to contain a small quantity of coumarin. These products would increase its density. The other ethers also usually contain small quantities of the coumarins they have been prepared from, which also would increase their densities. 
The magnetic rotary power of the methylic $\alpha$ - and $\beta$-methylorthoxyphenylacrylates shows a difference in the same direction, the $\alpha$ giving a lower result than the $\beta$, considerably greater than the variations of the densities would account for.

Dr. Gladstone's results show the same to hold good in the case of their refractive power.

These facts would seem to indicate that in the $\alpha$-compounds the groups, or some of them, contained in the molecules are farther apart than in the latter $\beta$-compounds.*

Should this be so, in what way would the properties of the $\alpha$-bodies be expected to differ from the $\beta$ ? One would imagine that any group or groups, being less intimately connected, would be more easily dissociated, and therefore that these bodies should be the least stable of the two.

There is no doubt that the $\alpha$-bodies are very much less stable than the $\beta$. For example, $\alpha$-coumaric acid cannot exist in the free state for any appreciable length of time, but splits up into coumarin and water. The same is true of its homologues. The $\alpha$-methylated acids and their ethers, although moderately stable, are not so stable as the corresponding $\beta$-compounds. Thus $\alpha$-methylorthoxyphenylcrotonic and angelic acids and their ethers, when treated with phosphoric chloride yield their coumarins, whereas the $\beta$-acids yield the chlorides of their radicals.

There is one point connected with this matter of isomerism worthy of note, and that is, that the changes of condition these bodies undergo are always associated with dehydration and rehydration. Thus $\beta$. coumaric acid on losing the elements of a molecule of water, becomes coumarin. This when hydrated does not go back to $\beta$-coumaric acid, but to its unstable isomeride $\alpha$-coumaric acid, and it is not until this (or rather its salt) is heated strongly that the original acid is reproduced. This suggests the thought, that if the $\alpha$-bodies differ from the $\beta$-owing to a difference of distance between the groups in the molecules, does this difference of proximity exist between all the groups, or only between some? The above observations respecting their formation would make it appear that it was only between the radical and the hydroxyls, as it is first seen on hydrating the cou-

* In the recently published new edition of Part III of "Miller's Chemistry," I find the following statement (p. 993) at the end of Chapter $X$, in which the Van't Hoff hypothesis of isomerism is discussed, and the insufficiency of this and of the ordinary hypothesis is pointed out:- "Are we not perhaps justified in supposing that there are two classes of isomerides-ordinary isomerides, in which the atoms occupy relatively different positions-and exceptional isomerides, in which the atoms occupy relatively similar positions, but in which they are situated at different distances?" 
marins. The difference of stability is also seen to be in connection with the hydroxyl.

These remarks also apply to the cases of maleic and fumaric acid, and citraconic and mesaconic acids, where we find the formation of maleic or citraconic acids resulting from the removal of a molecule of water from fumaric or mesaconic acids, and rehydration of the product. Maleic acid also appears to be less stable than fumaric, inasmuch as it is dehydrated by acetylic chloride, this reagent not acting on fumaric acid.*

It may be remarked in passing, that nearly all the bodies which are now called physical isomerides are hydroxylised products, and those containing the largest number of hydroxyls have the largest number of these isomerides, as in the case of the carbohydrates. Amongst the inorganic hydrates there are apparently isomeric bodies. Perhaps the soluble silicic acid, ferric oxide, and other analogous bodies are such. I hope to examine further into these peculiar kinds of isomerism from this point of view.

The formula I gave to phenylangelic acid some time since has been objected to by Fittig (Annalen, 195, 169), also by Baeyer (Ber., $13,115)$. It is the formula originally given to this body by Fittig and Bieber. Fittig and also Conrad and Bischoff (Annalen, 204, 182), likewise believe that the formula of phenylcrotonic acid should be the same as that which I proposed for the isophenylcrotonic acid from oil of bitter almonds and succinic anhydride. From the new facts which have been brought to bear on these subjects, I am quite inclined to believe in the conclusions they have arrived at, viz., that phenylangelic acid should be represented as-

$$
\mathrm{C}_{6} \mathrm{H}_{5}-\mathrm{CH}=\mathrm{C}<\underset{\mathrm{COOH}}{\mathrm{CH}_{2}-\mathrm{CH}_{3}} \text {, }
$$

and phenylcrotonic as-

$$
\mathrm{C}_{6} \mathrm{H}_{5}-\mathrm{CH}=\mathrm{C}<\mathrm{COOH}^{\mathrm{CH}_{3}}
$$

The analogous acids described in this paper would of course be similarly constituted. I am making some experiments on the phenylcrotonic and angelic acids and their bromine addition-products, which will I hope go to settle the formulæ of these acids. It is evident that if their constitution is correctly expressed above, they cannot yield homologues of propiolic acid.

As the coumarins and the $\alpha$ - and $\beta$-acids described in this paper form definite crystals, it was thought that their measurement would

* In one point maleic and fumaric do not correspond with the acids treated of in this paper, and that is in the boiling points of their ethers : that of maleic acid being higher than that of fumaric. 
be of special interest, first, because they are homologues, and it was hoped that some relationship might be seen for the difference of $\mathrm{CH}_{2}$; and secondly, the $\alpha$ and $\beta$ being physical isomerides, it was also hoped that some definite crystallographic relationship between them might be discovered.

Mr. L. Fletcher of the British Museum very kindly undertook the measurement of the crystals, and has examined all the following bodies, so we now have the following series (ordinary coumarin having been previously examined) :-

\section{Coumarin.}

$\alpha$ - and $\beta$-Methylorthoxyphenylacrylic acids.

Propionic coumarin.

$\alpha$ - and $\beta$-Methylorthoxyphenylcrotonic acids.

Butyric coumarin.

$\alpha$-Methylorthoxyphenylangelic acid.

I am sorry that I have not been able to get the $\beta$-methylorthoxyphenylangelic acid in a suitable state for measurement at present, and thus complete the series.

The following are Mr. Fletcher's results and observations :-

\section{Propionic Coumarin.}

System; Orthosymmetric or Rhombic.

Parameters:- $a: b: c:: 2 \cdot 1950: 1: 0 \cdot 4001$.

$$
110 \cdot 100=65^{\circ} 31^{\prime} ; 011 \cdot 010=68^{\circ} 12^{\prime} ; 101 \cdot 001=10^{\circ} 20^{\prime}
$$

Forms observed:- $a$ 100, $b$ 010, $n$ 101, $g$ 610, $p$ 111, $d 121$.

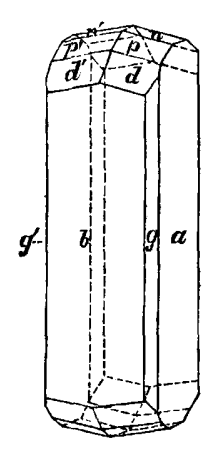

FIG. 1.

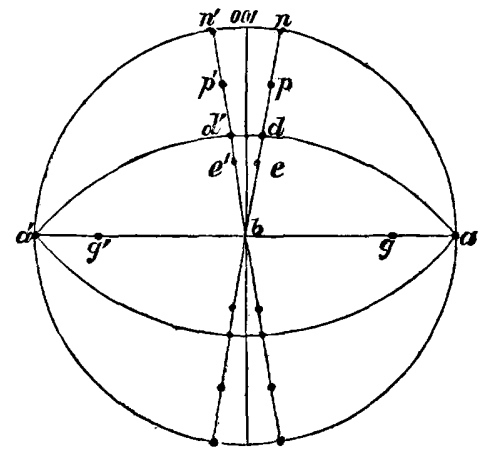

Fra. 2.

The faces $b$ are generally very prominently developed.

The only angles which could be measured with sufficient accuracy 
to serve for the determination of the parameters were: $a g, a d, p d, d b$. From observation of these angles on seven crystals the most probable values of the parameters were calculated by the method of least squares.

\begin{tabular}{|c|c|c|c|c|c|}
\hline \multirow{3}{*}{ Anglcs. } & \multirow[b]{2}{*}{ Calculated. } & \multicolumn{4}{|c|}{ Observed. } \\
\hline & & Mean of best angles. & & Limits. & \\
\hline & $20^{\circ} \quad 6^{\prime}$ & $20^{\circ} \quad 0^{\prime}$ & $19^{\circ}$ & $50^{\prime}-20^{\circ}$ & $9^{\prime}$ \\
\hline ad.... & $81 \quad 54$ & 82 & 81 & $23-82$ & 41 \\
\hline$p d \ldots$. & 44 & 16 & 15 & $40-17$ & 41 \\
\hline$d b \ldots$ & 47 & 51 & 51 & $1 \dot{y}-52$ & 8 \\
\hline
\end{tabular}

A crystal of a second lot presented a similar habit to that figured above : on closer examination, however, it proved that the prominent pyramidal form instead of being $d$ or (121) was $e$ or (131), a form not observed on the first crystals.

\section{Butyric Coumarin.}

System, Monosymmetric or Oblique.

$$
\begin{aligned}
& \text { Parameters : }-\mathrm{XOZ}=67^{\circ} 18^{\prime} ; a: b: c:: 1 \cdot 192: 1: 0 \cdot 694 . \\
& 001 \cdot 100=112^{\circ} 42^{\prime} ; 110 \cdot 010=42^{\circ} 17^{\prime} ; 011 \cdot 010=57^{\circ} 22^{\prime} .
\end{aligned}
$$

Forms observed :- $a 100, m 110, c 001, p 111, w 430$.

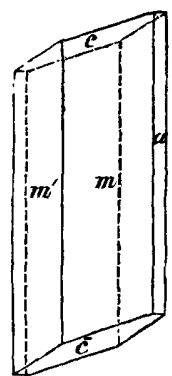

Fig. 3.

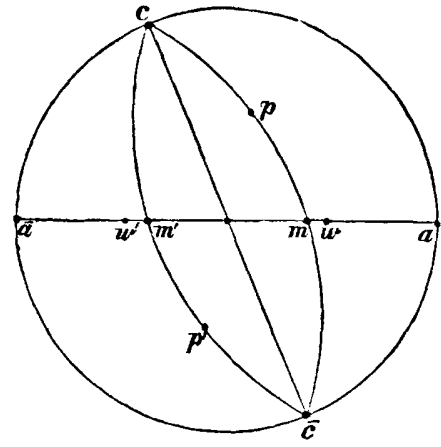

FIG. 4.

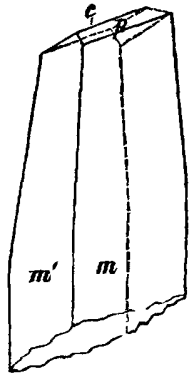

Fig. 5.

The crystals were very fragile, and often bollow; generally the summits were broken: no doubly-terminated crystal was discovered. The forms mac were occasionally well developed, as in Fig. 3 ; while very often the faces $m m^{\prime}$ were curred in the zones $m c, m^{\prime} c$, as shown in Fig. 5 ; on one crystal a small but distinct plane $p$ was observed, but as no image could be obtained the angle was determined by means of 
the position of maximum reflexion on observation with the micro. telescope; on this crystal the faces $\mathrm{mm}^{\prime}$ were curved through angles varying from $5-20^{\circ}$. The form $w$ was only imperfectly developed.

\begin{tabular}{crrrr} 
Angles. & \multicolumn{3}{c}{ Calculated. } & \multicolumn{2}{c}{ Observed. } \\
$m m^{\prime} \ldots \ldots \ldots$ & $84^{\circ}$ & $34^{\prime}$ & $84^{\circ}$ & $34^{\prime}$ \\
$m c \ldots \ldots \ldots$ & 105 & 3 & 105 & 3 \\
$m p \ldots \ldots \ldots$ & 57 & 53 & 57 & 53 \\
$m w \ldots \ldots \ldots$ & 8 & 12 & 7 & 52
\end{tabular}

a-Methy LORThoxy PhenylaCrylic ACID.

System, Monosymmetric or Oblique.

Parameters :- $\mathrm{XOZ}=87^{\circ} 12^{\prime} ; a: b: c:: 0 \cdot 677: 1: 1 \cdot 122$.

$$
001 \cdot 100=92^{\circ} 48^{\prime} ; 110 \cdot 010=55^{\circ} 56^{\prime} ; 011 \cdot 010=41^{\circ} 45^{\prime} \text {. }
$$

Forms observed:-a 100, $r 102$ curved, $p$ 111, l 011, m 110.

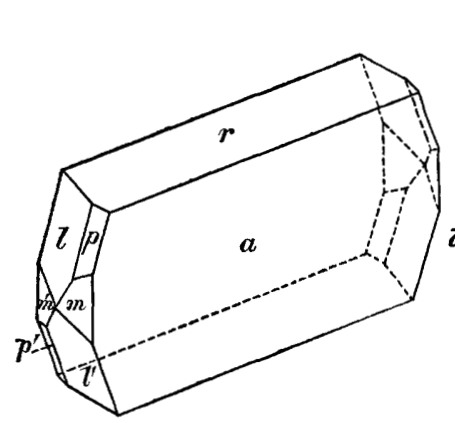

FIG. 6.

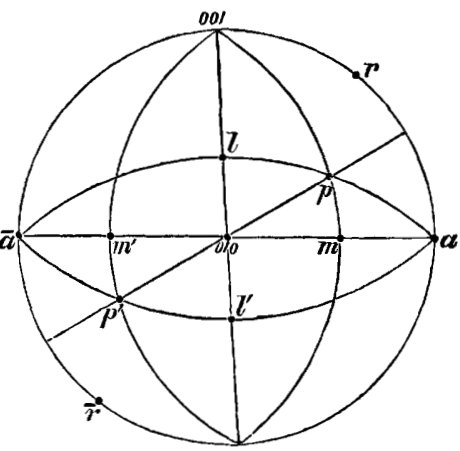

FIG. 7.

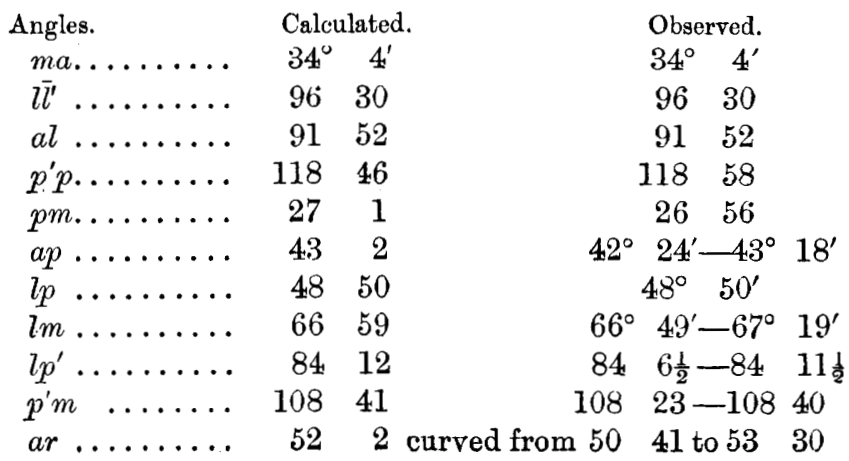


A larger crystal of a second growth presented a very different aspect, owing to the disappearance of the form $r$ (102), and to the intersection of the planes $l \bar{l}$ in an edge, as in the crystals of the corresponding $\beta$-acid next, described.

\section{$\beta$-MethylorthoxyphentaACRYLic ACID.}

System, Monosymmetric or Oblique.

Parameters $:-\mathrm{XOZ}=64^{\circ} 41^{\prime} ; a: b: c:: 0 \cdot 444: 1: 0 \cdot 807$.

$$
001 \cdot 100=115^{\circ} 19^{\prime} ; 110 \cdot 010=68^{\circ} 7^{\prime} ; 011 \cdot 010=53^{\circ} 54^{\prime} .
$$

Forms observed:- $a 100, b 010, m 110, l 011$.

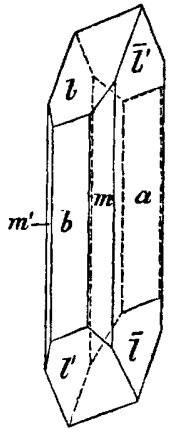

FIG. 8.

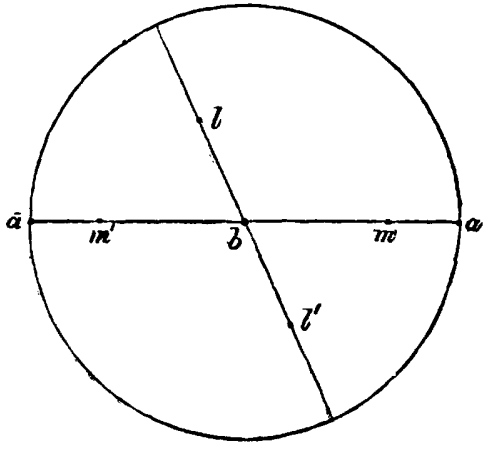

Fia. 9.

The crystals are generally tabular through the large development of the faces of the form $a$.

\begin{tabular}{crrrrr} 
Angles. & \multicolumn{2}{c}{ Calculated. } & \multicolumn{3}{l}{ Observed. } \\
$m b \ldots \ldots \ldots$ & $68^{\circ}$ & $7^{\prime}$ & & $68^{\circ} 11^{\prime}$ \\
$m \bar{m}{ }^{\prime} \ldots \ldots \ldots$ & 43 & 46 & & 43 & 45 \\
$l a \ldots \ldots \ldots$ & 110 & 13 & $109^{\circ}$ & $41^{\prime}-110^{\circ}$ & $53^{\prime}$ \\
$\bar{l} l^{\prime} \ldots \ldots \ldots \ldots$ & 72 & 12 & 72 & $13-72$ & 8 \\
$l b \ldots \ldots \ldots \ldots$ & 53 & 54 & 53 & $54-53$ & 32 \\
$l m \ldots \ldots \ldots \ldots$ & 95 & 43 & 95 & $48-96$ & 0
\end{tabular}

$\alpha$-Methylorthoxyphenylcrotonic Acid.

System, Monosymmetric or Oblique.

Parameters $:-\mathrm{XOZ}=64^{\circ} 54^{\prime} ; a: b: c:: 0 \cdot 863: 1: 1 \cdot 252$.

$$
001 \cdot 100=115^{\circ} 6^{\prime} ; 110 \cdot 010=52^{\circ} 0^{\prime} ; 011 \cdot 010=41^{\circ} 25^{\prime} \text {. }
$$

Forms observed: $-c 001, m$ 110, $l 011, n 101, l=\overline{1} 01$. 


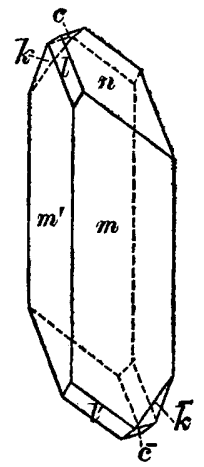

Fra. 10.

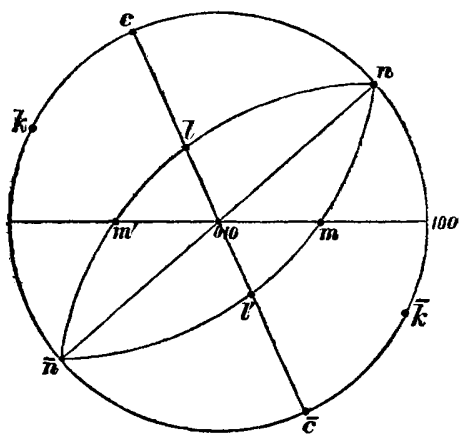

Frg. 11.

Many of the crystals were greatly distorted, the angles between faces which ought to have been parallel being in some cases as much as $2^{\circ}$ or $3^{\circ}$. The following observed angles are deduced from the measurement of ten crystals :-

\begin{tabular}{crrrrrrr}
\multicolumn{1}{l}{ Angles. } & \multicolumn{3}{c}{ Calculated. } & \multicolumn{3}{c}{ Means. } & \multicolumn{3}{c}{ Limits. } \\
$n c \ldots \ldots \ldots$ & $73^{\circ}$ & $42^{\prime}$ & $73^{\circ}$ & $4 \tilde{z}^{\prime}$ & $73^{\circ}$ & $11^{\prime}-74^{\circ}$ & $38^{\prime}$ \\
$c k \ldots \ldots \ldots$ & 39 & 8 & 39 & 8 & 38 & $49-39$ & 25 \\
$m m^{\prime} \ldots \ldots$ & 104 & 0 & 104 & 0 & 103 & $55-104$ & 9 \\
$c l \ldots \ldots \ldots$ & 48 & 35 & 48 & 6 & 46 & $27-49$ & 40 \\
$m n \ldots \ldots \ldots$ & 53 & 46 & 53 & 43 & 51 & $37-54$ & 5 \\
$n l \ldots \ldots \ldots$ & 79 & 18 & 79 & 33 & 76 & $59-81$ & 23 \\
$l m \ldots \ldots \ldots$ & 46 & 56 & \multicolumn{2}{c}{$\ldots \ldots$} & 45 & $50-48$ & 19
\end{tabular}

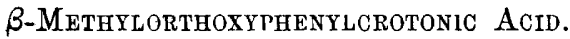

System, Monosymmetric or Oblique.

Parameters:- $\mathrm{XOZ}=84^{\circ} 18^{\prime} ; a: b: c:: 1 \cdot 281: 1: 0 \cdot 762$.

$$
001 \cdot 100=95^{\circ} 42^{\prime} ; 110 \cdot 010=51^{\circ} 53^{\prime} ; 011 \cdot 010=52^{\circ} 49^{\prime} \text {. }
$$

Forms observed :- $a$ 100, $v 320, m$ 110, $n$ 101, $c 001, p 111, g$ 122, 


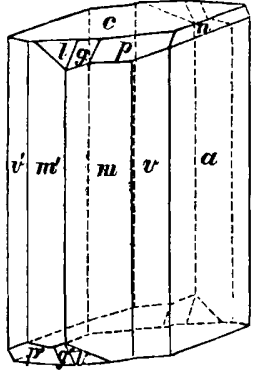

FIG. 12.

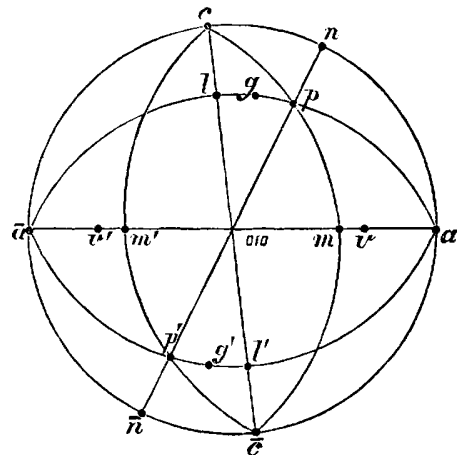

FIG. 13.

All the forms were well developed. The crystals were frequently twinned about the plane 100 .

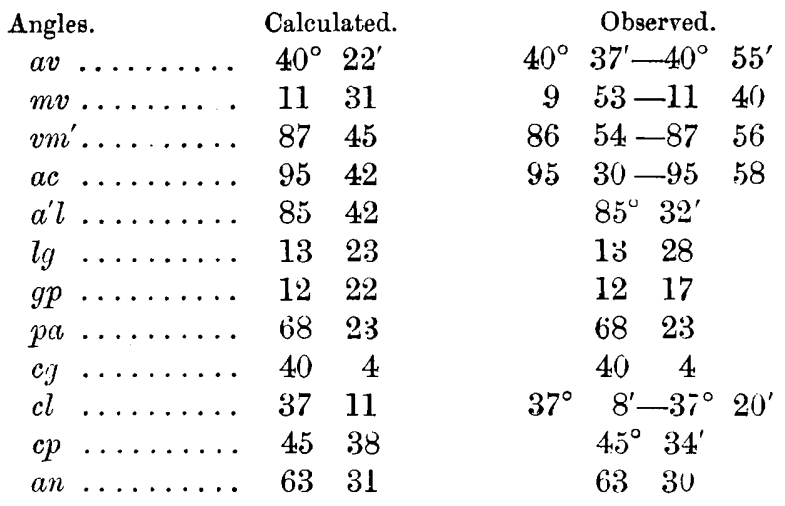

\section{a-Methylorthoxyphenthangelic Acio.}

System, Monosymmetric or Oblique.

Parameters $:-\mathrm{XOZ}=75^{\circ} 38^{\prime} ; a: b: c:: 1 \cdot 607: 1: 1 \cdot 963$.

$$
001 \cdot 100=104^{\circ} 22^{\prime} ; 110 \cdot 010=32^{\circ} 43^{\prime} ; 011 \cdot 010=27^{\circ} 44^{\prime} .
$$

Forms observed :-a 100, m 110, c 001, n 101, s 111 . 


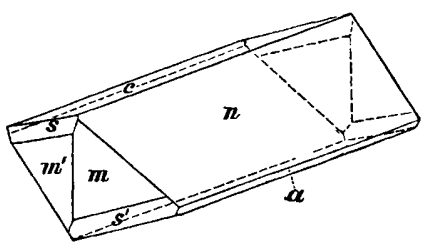

Fra. 14.

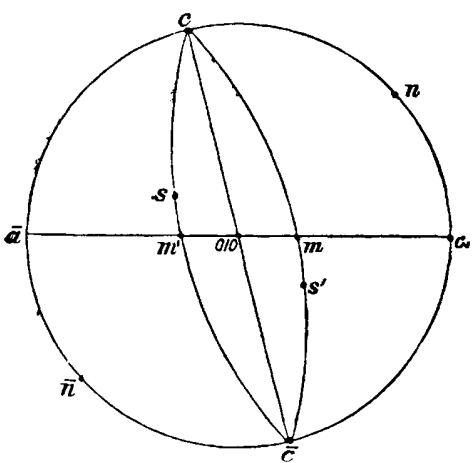

FIG. 15.

Angles. Calculated.

Observed.

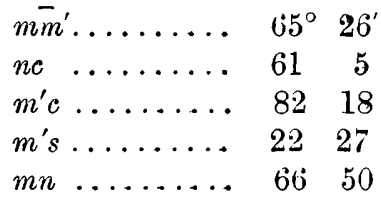

$65^{\circ} 25^{\prime}$

$61^{\circ} \quad 2^{\prime}-61^{\circ} \quad 5^{\prime}$

$82^{\circ} 16^{\prime}$

$21 \quad 12$ (about)

$66 \quad 50$

The results of the further investigation of the erystalline form of ordinary coumarin, and the $\beta$-methylorthoxyphenylangelic acid, as also of the optical series, $\mathrm{Mr}$. Fletcher hopes to eommunicate at some future time to the Crystallological Society, a prominent object of which is the discovery of relations existing between the composition and the geometrical and physical properties of erystals. 